\title{
Use of proteasome inhibitors in anticancer therapy
}

Sara M. Schmitt ${ }^{1}$, Lillian Lu ${ }^{1}$, Q. Ping Dou ${ }^{1}$

1 The Developmental Therapeutics Program, Barbara Ann Karmanos Cancer Institute, and Department of Oncology, Wayne State University School of Medicine, Detroit, MI, USA 48201

\section{Abstract}

The importance of the ubiquitin-proteasome pathway to cellular function has brought it to the forefront in the search for new anticancer therapies. The ubiquitin-proteasome pathway has proven promising in targeting various human cancers. The approval of the proteasome inhibitor bortezomib for clinical treatment of relapsed/refractory multiple myeloma and mantle cell lymphoma has validated the ubiquitin-proteasome as a rational target. Bortezomib has shown positive results in clinical use but some toxicity and side effects, as well as resistance, have been observed, indicating that further development of novel, less toxic drugs is necessary. Because less toxic drugs are necessary and drug development can be expensive and time-consuming, using existing drugs that can target the ubiquitin-proteasome pathway in new applications, such as cancer therapy, may be effective in expediting the regulatory process and bringing new drugs to the clinic. Toward this goal, previously approved drugs, such as disulfiram, as well as natural compounds found in common foods, such as green tea polyphenol (-)-EGCG and the flavonoid apigenin, have been investigated for their possible proteasome inhibitory and cell death inducing abilities. These compounds proved quite promising in preclinical studies and have now moved into clinical trials, with preliminary results that are encouraging. In addition to targeting the catalytic activity of the proteasome pathway, upstream regulators, such as the $19 \mathrm{~S}$ regulatory cap, as well as E1, E2, and E3, are now being investigated as potential drug targets. This review outlines the development of novel proteasome inhibitors from preclinical to clinical studies, highlighting their abilities to inhibit the tumor proteasome and induce apoptosis in several human cancers.

\section{Keywords}

Ubiquitin-proteasome pathway; Bortezomib; Anticancer therapy; Disulfiram; Natural compounds 


\section{Ubiquitin-proteasome pathway}

The ubiquitin-proteasome pathway (UPP) is critical to normal cellular function and, in 2004, the Nobel Prize in Chemistry was awarded to its discoverers [1,2]. The major responsibility of the ubiquitinproteasome pathway (Figure 1) is selective proteolytic degradation of proteins involved in various biological processes, including development, differentiation, proliferation, signal transduction, and apoptosis [3]. Because unbalanced protein homeostasis plays a vital role in the development, growth, and survival of malignancies [4], targeting factors involved in the synthesis and degradation of proteins as an anticancer strategy has been explored [5]. Increased proteasome activity has been observed in various cancers, such as prostate [6], colon [7], and leukemia [8], suggesting that cancer cells are more dependent on the ubiquitin-proteasome pathway than normal cells and that targeting this pathway in the treatment of human cancer is quite promising. Inhibition of the chymotrypsin (CT)-like activity of the tumor proteasome is associated with cell cycle arrest and induction of apoptosis [9,10], indicating that inhibition of the proteasome may efficiently cause selective killing/resting of cancer cells with little effect on normal cells but also sensitize resistant cancer cells to current chemo- or radiotherapy [11]. There are two steps in the ubiquitin-proteasome pathway (Figure 1) [12]:

- conjugation of multiple ubiquitin molecules to the target protein, and

- degradation of the ubiquitin-tagged protein by the $26 \mathrm{~S}$ proteasome.

The $26 \mathrm{~S}$ proteasome is a large $(2.5 \mathrm{MDa})$, multi-subunit complex that is localized in both the cytosol and the nucleus of cells [13-15]. The $26 \mathrm{~S}$ proteasome is comprised of the catalytic $20 \mathrm{~S}$ core and two $19 \mathrm{~S}$ regulatory caps (Figure 1) [16,17]. The $20 \mathrm{~S}$ core is made up of 28 subunits, arranged to form a barrellike structure of four alternately stacked rings: two non-catalytic alpha rings (seven subunits each) surrounding two catalytic beta rings (seven subunits each) [18-20]. The alpha subunits allow access to the proteasomal active sites only to unfolded proteins, while the beta subunits are responsible for the proteolytic activities of the proteasome [20]. There are three active beta subunits: beta-1, responsible for the caspase or peptidyl-glutamyl peptide-hydrolyzing (PGPH)-like activity, beta-2 for trypsin-like and beta-5 for chymotrypsin (CT)-like [20,21]. The catalytic activity of each active subunit is dependent on an amino terminal Thr1 residue, a nucleophile, which can be inhibited by some proteasome

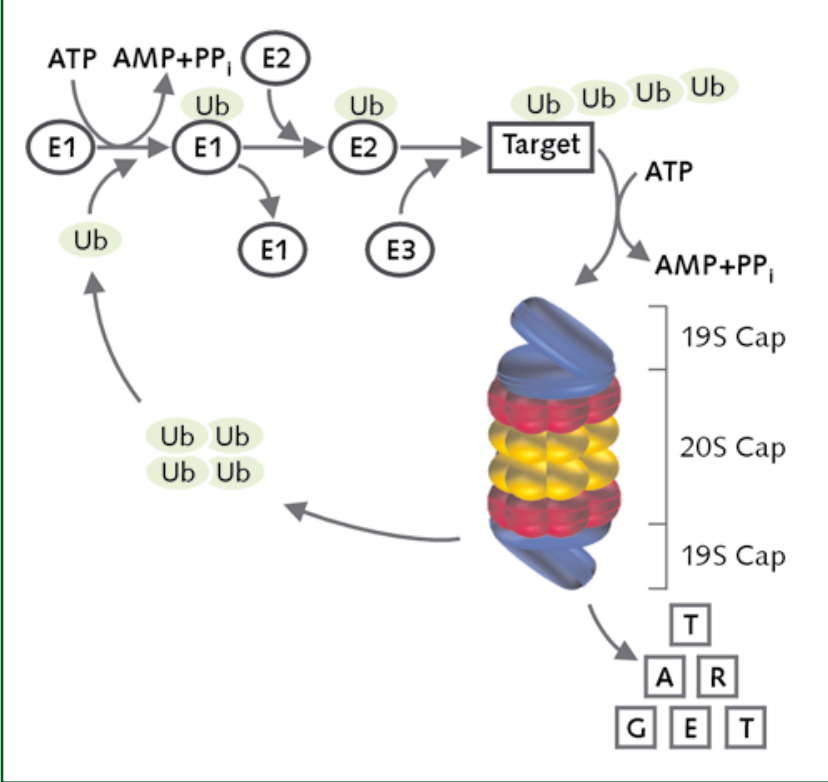

Figure 1. The ubiquitin-proteasome pathway inhibitors (such as bortezomib; Figure 2) through interactions with electrophilic motifs within their structures [19,22].

Also important for proper function are the six ATPase and at least eight non-ATPase subunits which are contained within the 195 regulatory cap $(700 \mathrm{kDa})$ and are necessary for the recognition, deubiquitination, unfolding, and translocation of target proteins before degradation by the $20 \mathrm{~S}$ core $[23,24]$. The $19 \mathrm{~S}$ regulatory cap can be divided into a base and a lid, with the base containing the six ATPase subunits, Rpt16, which form a hexameric ring [25-27] and two non-ATPases, Rpn-1 and -2 [28,29]. The base component is responsible for recognition and unfolding of the ubiquitinated proteins, as well as opening of the $20 \mathrm{~S}$ gate and translocation of target substrates into the core. The lid is composed of at least six non-ATPases, which contain ubiquitin receptors Rpn-10/S5A and Rpn-13/ 


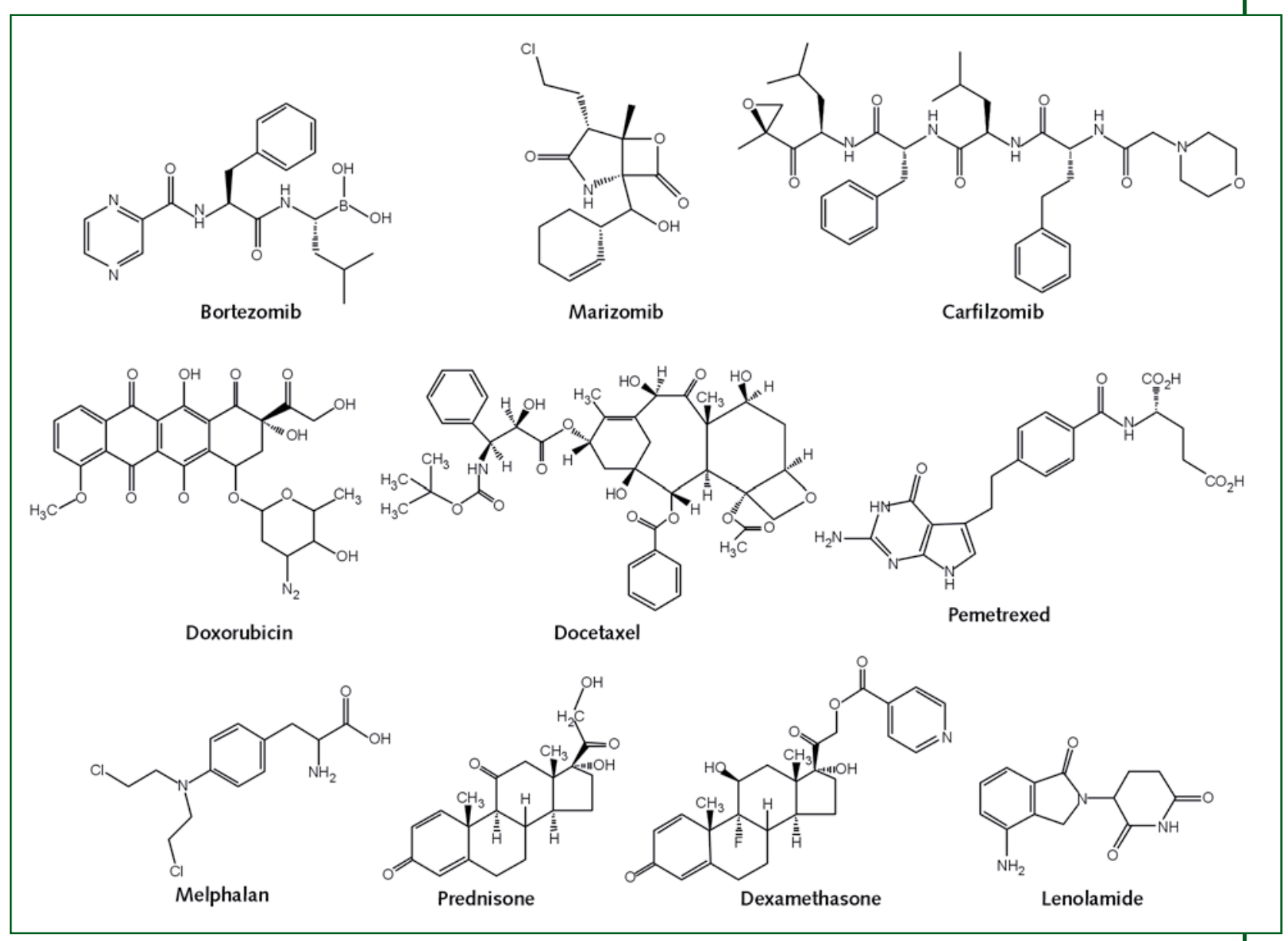

Figure 2. Structures of bortezomib, its second generation drugs marizomib and carfilzomib, and drugs with which it has been tested in clinical trials including doxorubicin, docetaxel, melphalan, prednisone, dexamethasone, lenolamide and pemetrexed

Adrm1 [30]. The Rpn-10/S5A receptor has two ubiquitin interacting motifs which have a higher affinity for poly-ubiquitinated proteins [31]. Rpn-13/Adrm1 is important in the deubiqitination of proteins, as it binds to the non-ATPase Rpn2 to recruit some deubiquitinating enzymes (DUBs) to the proteasome [32-34]. Deubiquitination is a very highly regulated process which is important for recycling of ubiquitin molecules and controlling the rate of ubiquitin-dependent proteasomal degradation [35]. The ubiquitination step of the UPP is characterized by three different enzymes, E1, E2, and E3 (Figure 1). The UPP begins with ATP-dependent E1-mediated activation of ubiquitin, a 76 amino acid protein that is ubiquitously expressed and serves as a tag for target proteins destined for degradation by the UPP (Figure 1), except in rare cases such as MODC and HIF- $1 \alpha$, which require no ubiquitination for proteasomal degradation [36-38]. Activated ubiquitin is then transferred from E1 to E2, which is responsible for ubiquitin conjugation, and to E3, the ubiquitin-ligating enzyme, which then aids in the transfer of active ubiquitin to lysine residues within the target protein [39,40]. The ubiquitin-tagged target protein is then transported to the $26 \mathrm{~S}$ proteasome, where degradation occurs and the ubiquitin molecules are released for recycling (Figure 1) [41]. This tightly regulated process is crucial for the regulation of many cellular processes, including those involved in tumorigenesis [42], which makes it a promising target for anti-cancer therapeutic agents.

In addition to its critical role in protein homeostasis, the proteasome also functions in several nonproteolytic processes. These include transcription-coupled nucleotide excision repair [43], initiation 
and elongation of transcription [44] and regulation of gene expression [45]. The 19S regulatory subunit possesses chaperone-like activity that is important in efficient transcriptional elongation by remodeling and stabilization of RNA polymerase II and the FACT complex, which physically interact with the proteasome [46]. Importantly, in addition to the proteasome pathway, ubiquitin is also involved in membrane-trafficking, protein kinase activation, DNA repair and chromatin remodeling [47].

Because ubiquitin is involved in several processes, it is no surprise that there are several ubiquitin-like proteins (Ubls) that are structurally similar to ubiquitin and also post-translationally modify proteins in a pathway separate from that of ubiquitin. Two examples of Ubls include SUMO/Sentrin and NEDD8. SUMO (small ubiquitin-like modifier) functions in may cellular processes including cell cycle control, nuclear transport and responses to viral infections, and aberrant sumoylation has been implicated in various diseases [48]. There are three isoforms: SUMO-1, -2 and -3, of which -2 and -3 are essentially identical, containing a sumoylation motif around K11 which allows formation of poly-SUMO chains, and function differently than -1 , which has no sumoylation motif and therefore cannot form chains $[49,50]$. SUMO-1 does contain an ubiquitin-homology domain that is $18 \%$ identical and $48 \%$ homologous to human ubiquitin and has gly-gly residues which are necessary for conjugation [51-55]. Proteins to be sumoylated are activated by the E1 AOS1 (28\% identical/56\% similar to N-terminal half of ubiquitin) -UBA2 (homologous to C-terminal half of ubiquitin [56-59], conjugated by the E2 UBC9 [54,60-64], and ligated by one of three E3 enzymes, RanBP2, PIAS, and Polycomb protein Pc2. Many protein targets of SUMO are involved in transcription, DNA repair and maintenance of chromatin structure and sumoylation of these targets is modulated by acetylation and phosphorylation [48]. Interestingly, in some cases sumoylation seems to oppose ubiquitination. For example, ubiquitination of I $\mathrm{B}$ (inhibitor of NF$\kappa \mathrm{B})$ leads to degradation of the protein, while sumoylation leads to stabilization [65].

Another important ubiquitin-like protein is NEDD8 (neural precursor cell-expressed developmentally-downregulated), which is enriched in the nucleus and weak in the cytosol, unlike ubiquitin, which exists equally in the nucleus and cytosol [66]. NEDD8 is not a direct signal for degradation but a regulator of E3 ubiquitin ligases and all of its known substrates are members of the cullin family of proteins, which bind RING-finger proteins to recruit E2 enzymes [67-70]. NEDD8 contains a C-terminal glycine [66] that is activated by the E1 APPB1 (28\% identical/56\% similar to N-terminal half of the ubiquitin E1) -UBA3 (homologous to C-terminal half) [68,71-74]. Activated NEDD8 is then transferred to its substrate by the $\mathrm{E} 2 \mathrm{UBC} 12[68,71,74]$ and its removal is dependent on the proteases USP21, DEN/NEDP1 and COP1.

Importantly, like ubiquitin, these and other ubiquitin-like proteins have been implicated in the pathogenesis of some human diseases, including cancer. For instance, mutations in SUMO have been reported in retinoblastoma and melanoma [75,76], and dysregulation has been observed in several other cancers, such as lung, prostate, breast, colon, brain, hepatocellular and ovarian [77-79]. Similarly, NEDD8 downregulation has been reported in prostate carcinomas [80]. Therefore, due to their importance in normal cellular processes and apparent roles in cancer progression, these ubiquitin-like proteins may also serve as putative drug targets. In fact, targeting the SUMO E2 enzyme UBC9, which is upregulated in some human malignancies, is already being investigated [79,81].

\section{Targeting the $20 \mathrm{~S}$ proteasomal core}

\section{The proteasome inhibitor anticancer drug bortezomib}

\section{Properties, biological effects and mechanisms of action of bortezomib}

Bortezomib, a dipeptide boronic acid derivative first synthesized in 1995 by Myogenics Company and called MG-341, contains pyrazinoic acid, phenylalanine and leucine in its structure (Figure 2). After 
promising results from in vitro and in vivo studies and a small phase I clinical trial, it was renamed PS-341 and purchased by Millenium Pharmaceuticals. Bortezomib has demonstrated considerable apoptotic inducing activity in a range of tumor cell lines and animal models [82-84]. In 2003, seven years after it was initially synthesized, the US Food and Drug Administration approved bortezomib $\left(\right.$ Velcade $^{\circledast}$ ) for the treatment of multiple myeloma.

The molecular formula of bortezomib is $\mathrm{C}_{19} \mathrm{H}_{25} \mathrm{BN}_{4} \mathrm{O}_{4}$ and its chemical IUPAC name is [3-methyl1-(3-phenyl-2-pyrazin-2-ylcarbonylamino-propanoyl) amino-butyl] boronic acid (Figure 2). Phase I clinical trials revealed that bortezomib distributes to the plasma within ten minutes of IV injection and is able to enter nearly all tissues except brain and adipose tissues [85-88]. Bortezomib is metabolized through cytochrome p450 mediated intracellular oxidative deboronation [89] and its half-life is more than 40 hours [87].

Bortezomib induces apoptosis through reversible inhibition of the $26 \mathrm{~S}$ proteasome. Inhibited proteasome activity usually recovers within 72 hours after administration [90]. Proteasome activity is inhibited when the boronic acid group in bortezomib binds to and forms a complex with the threonine hydroxyl group in the active site of the $\beta 5$-subunit, which ultimately results in cell death [91]. Although success with bortezomib has been achieved in hematological malignancies, less than encouraging results have been observed in solid tumors [92,93]. In addition to its use as a single agent, the effects of bortezomib in combination with conventional chemotherapeutics have been investigated and the results were quite encouraging [94-100].

The results of several preclinical studies demonstrated the potency of bortezomib in vitro against human tumor cells and in vivo in xenograft animal models. In a standard NCI-60 screen, bortezomib was found to potently inhibit cell proliferation [82] and apoptosis was observed in vitro in many malignant cells including multiple myeloma, prostate, pancreatic, renal and squamous cell carcinomas [101-106]. Importantly, the antitumor activity of bortezomib was observed in both chemoresistant and chemosensitive myeloma cells and the sensitivity of resistant cells to chemotherapy was increased significantly when combined with a sublethal dose of bortezomib with no effect on normal hematopoietic cells $[107,108]$. Additionally, in an in vitro study of four ovarian and three prostate cancer cell lines, bortezomib had comparable effects on cells derived from solid tumors and hematological malignancies [83]. Bortezomib was also able to potently inhibit the growth of multiple myeloma xenografts in mice [109].

Preclinical studies have revealed that bortezomib has multiple targets in malignant cells. One possible mechanism may be activation of NOXA [110]. NOXA (Latin for damage) is a pro-apoptotic member of the Bcl-2 family [111] and is involved in p53-mediated apoptosis. Noxa gene expression is associated with direct activation of its promoter by p53 [111]. Chemo- or radiotherapy-mediated apoptosis occurs through upregulation of p53 and subsequent Noxa gene expression. NOXA upregulation has been shown to induce apoptosis through interaction with, and inhibition of the anti-apoptotic proteins Bcl$\mathrm{X}_{\mathrm{L}}$ and Bcl-2 or stimulation of other pro-apoptotoic factors [19,112,113]. Importantly, one study has shown that bortezomib treatment in myeloma and melanoma cell lines resulted in p53-independent induction of NOXA and blockade of NOXA induction with an antisense oligonucleotide caused only $30 \%$ to $50 \%$ reduction in apoptosis [110]. Bortezomib can induce NOXA in a variety of tumor cell lines with defective p53 signaling [114], and clinical studies indicate that bortezomib can suppress tumor growth in a p53-independent manner [16,115]. One study has shown that bortezomib treatment in myeloma and melanoma cell lines resulted in p53-independent induction of NOXA and blockade of NOXA induction with an antisense oligonucleotide caused only $30 \%$ to $50 \%$ reduction in apoptosis [110]. Importantly, NOXA induction by bortezomib occurs preferentially in cancer cells compared to normal cells [110, 116]. While bortezomib selectively caused a 20- to 60-fold induction of NOXA in melanoma cells, levels were unaffected in normal melanocytes [110,116,117].

Reports have also suggested that suppression of the NF- $\kappa \mathrm{B}$ signaling pathway may be another key mechanism associated with the activity of bortezomib [16]. NF- $\kappa \mathrm{B}$ is a p50/p65 heterodimeric tran- 
scription factor that usually exists in an inactive form in the cytoplasm bound to its inhibitory protein, $\mathrm{I} \kappa \mathrm{B}$. Upon degradation of $\mathrm{I} \kappa \mathrm{B}$, the active NF- $\kappa \mathrm{B}$ complex can translocate into the nucleus where it stimulates the expression of various genes including cytokines (IL-6, TNF- $\alpha$ ), survival factors (IAPs, Bcl$\mathrm{X}_{\mathrm{L}}$ ), and insulin-like growth factor-I (IGF-I), which results in proliferation, resistance to apoptosis and drug-resistance in cancer cells [118]. In drug-resistant multiple myeloma cells that have been shown to express higher NF- $\kappa \mathrm{B}$ activity than drug-sensitive multiple myeloma cells $[107,119]$, bortezomib prevents degradation of $I \kappa B$, thus blocking NF- $\kappa B$ activation as well as suppressing expression of related cytokines and survival factors. Conversely, studies have also shown that the NF- $\kappa \mathrm{B}$ may not be important to the anti-tumor activity of bortezomib. In a study of mice bearing human multiple myeloma cells, treatment with bortezomib was associated with activation of NF- $\kappa \mathrm{B}$, rather than inhibition [120]. Other possible mechanisms by which bortezomib causes apoptosis include disruption of the interaction between tumor cells and dendritic cells [121]; induction of endoplasmic reticulum (ER) stress and generation of reactive oxygen species (ROS) [122,123]; inhibition of angiogenesis in human myeloma, pancreatic and squamous cell carcinoma xenografts [106,124]; induction of extrinsic and intrinsic apoptotic pathways via activation of caspases-8 and -9 [125,126]; and activation of the p38 mitogenactivated protein kinase (MAPK) pathway [127]. Usually multiple targets may play important roles in induction of apoptosis by bortezomib in some cancer cells while different targets may be critical in other cells.

\section{Bortezomib in clinical trials}

\section{Phase I clinical trials of bortezomib}

After the success achieved in preclinical studies, several clinical trials evaluating the effectiveness of bortezomib for the treatment of multiple myeloma in patients have been completed. In a dose-defining phase I trial investigating bortezomib as a single agent, bortezomib induced a dose-dependent inhibition of 20 S proteasome activity from $36 \%, 60 \%, 65 \%$, to $74 \%$, after 1 hour treatment of bortezomib at $0.40,1.04,1.20$, and $1.38 \mathrm{mg} / \mathrm{m}^{2}$ doses, respectively [128]. The results of this study of 27 patients with relapsed multiple myeloma confirmed preclinical findings that bortezomib could inhibit proteasome activity in a dose- and time-dependent manner. The highest dose of bortezomib tested, $1.04 \mathrm{mg} / \mathrm{m}^{2}$, was well tolerated and of the nine patients that completed at least one full cycle and were assessable for response, one had a complete response and eight showed improvement in paraprotein levels and marrow plasmacytosis [128].

In another phase I clinical trial bortezomib was used in combination with doxorubicin (Figure 2). Forty-two patients with advanced hematologic malignancies were enrolled to obtain preliminary response data and to determine the maximum tolerated dose (MTD) and dose-limiting toxicities (DLTs). The maximum tolerated dose was $1.30 \mathrm{mg} / \mathrm{m}^{2}$ and the most common adverse effects were fatigue (88\%), thrombocytopenia (69\%), lymphopenia (64\%), nausea (64\%), constipation (60\%), peripheral neuropathy (55\%), and anemia (52\%) [98]. In another clinical trial evaluating 22 multiple myeloma patients with a combination of bortezomib and doxorubicin, eight patients had a complete response (CR, 36\%) or near-CR, and another eight had partial responses (PRs, 36\%) [98].

Other phase I clinical trials have also investigated the effects of bortezomib either alone or in combination on solid tumors. Bortezomib as a single agent showed anti-tumor activity in patients with advanced androgen-independent prostate cancer [129], and an overall response rate of $47 \%$ was observed in recurrent ovarian or primary peritoneal cancer after treatment with bortezomib in combination with carboplatin (Figure 3) [130]. No significant responses were observed in patients with aggressive metastatic breast cancer or neuroendocrine tumors treated with bortezomib alone [38,131,132]. Similarly, in a study of patients with hormone refractory prostate cancer and castrate-resistant metastatic prostate cancer [133], no significant responses were seen after treatment with bortezomib in combination with either docetaxel [134] or prednisone (Figure 2) [135]. 


\section{Phase II clinical trials of bortezomib}

Following the promising results of phase I trials, a large phase II trial was performed [136]. In the SUMMIT (Study of Uncontrolled Multiple Myeloma Managed with Proteasome Inhibition Therapy) trial, 202 patients with relapsed or refractory myeloma who had previously been treated were enrolled. Patients were treated with $1.3 \mathrm{mg} / \mathrm{m}^{2}$ bortezomib on days $1,4,8$, and 11 of a 3-week cycle for as many as eight cycles. An overall response rate (complete response + partial response + minimal response) of $35 \%$, including $4 \%$ CR, $6 \%$ with near-CR and $18 \%$ with $\mathrm{PR}$, was achieved in patients treated with bortezomib alone [136]. In the CREST (Clinical Response and Efficacy Study of Bortezomib in the Treatment of Relapsing Multiple Myeloma) phase II trial, 67 patients with relapsed/refractory multiple myeloma were enrolled [137]. Patients were randomly divided into two groups, receiving either 1.0 or $1.3 \mathrm{mg} / \mathrm{m}^{2}$ of bortezomib and anticancer activity was observed. This study showed that bortezomib was still effective at a dose of $1.0 \mathrm{mg} / \mathrm{m}^{2}$ for relapsed multiple myeloma patients with attenuating doseassociated toxicity [137].

Two other phase II trials investigated the efficaciousness of bortezomib in combination with conventional chemotherapeutic agents. A study of 32 patients with previously untreated symptomatic multiple myeloma compared the effects of bortezomib as a single agent versus in combination with dexamethasone (Figure 2) [11]. All patients completed the first two cycles of bortezomib alone, with $3 \%$ of patients reaching CR, $9 \%$ near CR and $28 \%$ PR. Of the 32 patients, 22 were treated with a combination of bortezomib and dexamethasone and an increased response was seen in 15 of 22 patients (68\%) [11]. In another study, relapsed multiple myeloma patients were treated with a combination of bortezomib, doxorubicin and dexamethasone (Figure 2) [138]. Twenty of 21 patients (95\%) achieved at least a partial response (PR), including CR in $43 \%$, near-CR in $14 \%$, very good PR in $24 \%$, and PR in $14 \%$ [138].

Importantly, the efficacy of bortezomib against mantle cell lymphoma and non-Hodgkin's lymphoma has also been investigated in phase II clinical trials. In one study of pretreated and untreated mantle cell lymphoma, treatment with bortezomib $\left(1.3 \mathrm{mg} / \mathrm{m}^{2}\right)$ resulted in $46.2 \%$ and $46.7 \%$ response rates, respectively, suggesting that bortezomib may be quite effective for the treatment of mantle cell lymphoma [139]. Another trial showed a 58\% overall response rate after treatment with bortezomib in patients with indolent non-Hodgkin's lymphoma and mantle cell lymphoma [140]. Similarly, a phase II study evaluating the use of bortezomib and pemetrexed (Figure 2) alone or in combination in advanced NSCLC that had been previously treated was also conducted. No significant response or survival advantage was observed, but bortezomib was better tolerated when given in combination with pemetrexed [141], and several clinical trials are being conducted to continue to explore the use of bortezomib as a treatment for NSCLC. Unfortunately, other studies investigating the use of bortezomib against solid tumors have yielded disappointing results.

\section{Phase III clinical trials of bortezomib}

Based on the results of the phase II trials, a large international phase III trial in patients with relapsed multiple myeloma who had received 1-3 prior therapies was performed to compare the effects of bortezomib with those of high-dose dexamethasone [104]. Patients $(n=669)$ received either $1.3 \mathrm{mg} /$ $\mathrm{m}^{2}$ bortezomib (twice weekly for 2 weeks followed by a 1 week rest; intravenously) or high-dose dexamethasone (40 mg orally). The combined complete and partial response rates were 38\% and $18 \%$ for bortezomib and dexamethasone $(p<0.001)$, respectively, with median times to progression of 6.22 months in the bortezomib group versus 3.29 months in the dexamethasone group. Among patients taking bortezomib the one-year survival rate was $80 \%$, while that for patients taking dexamethasone was $66 \%(p=0.003)$ [104]. This trial demonstrated the advantage of bortezomib treatment compared with dexamethasone in terms of response rate, time to progression, and survival [104].

The phase III APEX (Assessment of Proteasome Inhibition for Extending Remissions) study evaluated patients with relapsed myeloma and assessed the impact of dose-modification on the severity and re- 
versibility of peripheral neuropathy associated with bortezomib treatment [142]. After $1.3 \mathrm{mg} / \mathrm{m}^{2}$ bortezomib for eight 21 -day cycles followed by three 35 -day cycles, $37 \%$ patients (124/331) had peripheral neuropathy that could be improved by dose modification without adverse effects on the outcome [142], suggesting that bortezomib-associated peripheral neuropathy is not only manageable, but also reversible in most relapsed myeloma patients. In another study of 638 patients with relapsed/refractory multiple myeloma, patients received $1.3 \mathrm{mg} / \mathrm{m}^{2}$ bortezomib on days $1,4,8$, and 11 of a maximum of eight 3 -week cycles (median $=5$ cycles) [143]. An overall response rate of $67 \%$, including $11 \% \mathrm{CR}, 22 \%$ near $\mathrm{CR}, 18 \% \mathrm{PR}$ and minimal response in 16\%, was achieved. On the day of and day after each bortezomib dose, $20 \mathrm{mg} /$ die dexamethasone was added after completion of at least two cycles for progressive and at least four for stable disease. Of the 208 patients that received dexamethasone, enhanced response was observed in 70 patients (34\%). Overall, the study showed that bortezomib, alone or in combination with dexamethasone, is both safe and effective for the treatment of relapsed/refractory multiple myeloma in patients with prior treatment [143].

The efficacy of bortezomib in combination with other conventional chemotherapeutics was investigated in another phase III trial [144]. Bortezomib in combination with dexamethasone (VD) or with dexamethasone and lenalidomide (VRD; Figure 2) as primary first-line treatment for multiple myeloma was examined in this study. Patients who had received previous dexamethasone-based treatments were enrolled to determine if better prolonged disease control results from switching to a proteasome inhibitor (VD arm) or from adding a proteasome inhibitor (VRD arm) to the current treatment. Complete results have not yet been published [144].

Another large phase III trial investigating bortezomib in combination treatments was conducted at 151 centers in 22 countries. Multiple myeloma patients who had received no previous treatments $(\mathrm{n}=682)$ were randomly divided into treatment groups receiving either either a combination of bortezomib plus melphalan-prednisone or melphalan-prednisone (Figure 2) alone [145]. This trial showed that bortezomib plus melphalan-prednisone may provide a valuable front-line treatment for myeloma patients and that the standard of care should no longer be melphalan-prednisone alone [145]. Most recently, in the phase III VISTA trial, combinations of bortezomib plus melphalan and prednisone compared with melphalan and prednisone were tested in previously untreated multiple myeloma. After prolonged follow-up (median 36.7 months), the data from this trial were analyzed. This follow-up not only validated the original study results, but also indicated that bortezomib-based drugs as first-line treatments afford greater survival advantage than treatment with conventional drugs followed by salvage with bortezomib-based treatments [146]. Additionally, initial treatment with bortezomib leads to lesser or equal amounts of resistance to subsequent therapies as compared to initial treatment with traditional chemotherapeutics [146]. Overall, the preclinical and clinical trials evaluating the use of bortezomib in vitro and in vivo have shown that the use of proteasome inhibitors as anti-cancer agents is a promising approach and should be further investigated.

However, although bortezomib has been used successfully in the clinic, adverse effects as well as resistance have been observed, suggesting that further development of drugs like bortezomib is necessary in order to reduce toxicity. In fact, some second generation proteasome inhibitors, marizomib and carfilzomib (Figure 2) [147,148] with different chemical and biochemical properties compared to bortezomib, have been developed in the search for novel, less toxic inhibitors. Additionally, other inhibitors that target the specialized immunoproteasome (Immunoproteasome-Specific Inhibitors) [148], natural compounds that are unable to interact with bortezomib and old copper-binding drugs may be much more potent with significantly less dose-limiting toxicities than some of the currently approved drugs [149]. Use of these novel inhibitors may also overcome bortezomib resistance or sensitize resistant tumor cells to bortezomib treatment, which could potentially result in dramatically increased success in the clinic. 


\section{Disulfiram-copper complexes as proteasome inhibitors}

Due to the importance of several metals to normal cellular function, the use of compounds that can bind important biological metals may be useful in the treatment of cancer. Some of these compounds, such as dithiocarbamates, have already been approved for the treatment of other ailments, and preclinical studies have proven their potential usefulness as anti-cancer agents. Some of these metal complexes have potent proteasome-inhibitory activities in cancer cells.

\section{Metals in cancer development and therapy}

The discovery that metals like copper and zinc are altered in tumors led to extensive research regarding the roles of these metals in the development and progression of human cancers as well as their potential as anti-cancer therapeutics. High serum and tissue levels of copper have been reported in several tumor types including colon [150], lung [151], prostate [150,152], breast [153,154] and brain [155]. Studies have shown a role for copper as a co-factor in angiogenesis through its ability to induce VEGF mRNA transcription as well as protein expression [156,157]. These studies led to the investigation of copper chelators for anti-angiogenic therapy in cancer treatment regimens [158,159].

Zinc, like copper, plays a key role in cellular processes, including defense against free radicals and proliferation [43-44] as well as being structurally important to several proteins and enzymes [160,161]. Zinc has also been implicated in apoptosis, but this role appears complex and cell-type specific [162-165]. Additionally, studies have shown an association between altered $\mathrm{Zn}$ levels and systemic abnormalities such as cancer [166], though this, like its role in apoptosis, appears cell-type specific and a firm relationship between zinc levels and tumor development has not yet been established $[164,167,168]$.

Copper and zinc are not only essential to critical biological processes such as tumorigenesis, but they have also been investigated as possible anticancer targets and as metal centers in anticancer drugs, especially following the discovery that some metal-based compounds, such as cisplatin (Figure 3), possess potent anti-cancer properties. Since its discovery, over $90 \%$ of testicular cancer cases have been cured by cisplatin, and it has also been important in the treatment of several other types of cancer, including bladder, cervical, head and neck, lymphoma, melanoma and ovarian [169]. Cisplatin causes apoptosis via its interaction with DNA and formation of adducts which interfere with replication and transcription [170]. After thorough investigation, a (Pt)-GG intrastrand cross-link has been found to be responsible for the cytotoxicity of cisplatin [171]. Unfortunately, the toxicities and drug resistance, both intrinsic and acquired, associated with cisplatin have hindered its widespread clinical use [172, 173]. The success and limitations of cisplatin have spurred the search for new, less-toxic metal-based complexes, employing $\mathrm{Cu}, \mathrm{Zn}, \mathrm{Ga}, \mathrm{Au}, \mathrm{Sn}$ and many other metals, as well as second generation platinum drugs like carboplatin (Figure 3). In

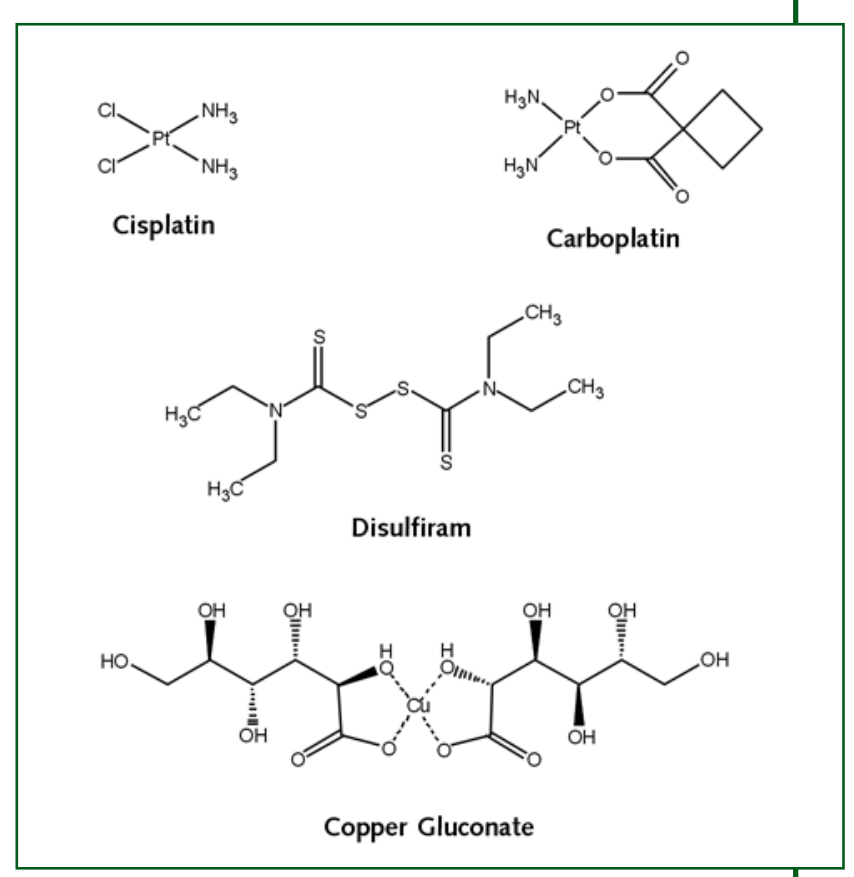

Figure 3. Structures of cisplatin, carboplatin, disulfiram and copper gluconate. Cisplatin has been used for decades to successfully treat testicular cancer. Carboplatin is a second-generation platinum drug that has been used in combination with bortezomib in clinical trials. Disulfiram is a copper chelator and is currently in clinical trials in combination with copper gluconate 
designing these putative drugs, keeping in mind important properties that may affect the activities of these compounds is important. For example, activity is not solely governed by the presence of the metal itself, but can also be influenced by the oxidation state, number and type of ligand bound, and the coordination geometry of the complex. Other important properties that can play a role in the activity of metal complexes include kinetic lability, redox behavior, and electric charge/radius ratio. The functional importance of metals, such as copper and zinc, to normal cellular homeostasis coupled with the success of metal-containing chemotherapeutics has resulted in studies investigating chelation of these vital metals with metal-chelators. One example of metal-chelating compounds is dithiocarbamates, which include several drugs that have been previously approved for use in the treatment of various diseases, including bacterial and fungal infections, AIDS, and alcoholism [174-176]. Taking advantage of the approval of drugs used to treat different conditions which have also been shown to function as metal chelators is an exciting concept in the field of cancer drug development and design. Previously approved drugs, such as disulfiram (DSF, Figure 3), that may form metal complexes with copper and zinc, have been explored as potential proteasome inhibitors that may serve as novel anticancer agents.

\section{Preclinical data with DSF}

Disulfiram (tetraethylthiuram disulfide, DSF) (Figure 3) is an irreversible inhibitor of aldehyde dehydrogenase, and is one of only two US FDA-approved drugs for the treatment of alcoholism [177179]. DSF contains an R1R2NC (S)SR3 functional group, with sulfhydryl groups that can react with $\mathrm{Cu}(\mathrm{II})$ [180]. This DSF-Cu reaction was confirmed by color-change experiment when DSF and $\mathrm{CuCl}_{2}$ were mixed at a 1:1 ratio [181]. While DSF is not able to interact with other bioavailable metals such as Fe (II or III) or Mn (III) [180], studies have shown that DSF is able to bind Zn(II). One report demonstrated that $\mathrm{Zn}$ (II) supplementation potentiated DSF treatment in melanoma and hepatic cancer [182] and our lab has found that DSF-Zn complex can inhibit the proteasome, albeit at a weaker potency than DSF-Cu. Importantly, studies have also shown that during its absorption into the gastrointestinal system, DSF is promptly converted to its copper complex [177].

We have reported that DSF when complexed with Cu could potently inhibit both purified 20 S proteasome $\left(\mathrm{IC}_{50}=7.5 \mu \mathrm{M}\right)$ and intact $26 \mathrm{~S}$ proteasome in MDA-MB-231 breast cancer cell lysates $(20 \mu \mathrm{M})$. Inhibition of CT-like activity by $>95 \%$ and proliferation by up to $85 \%$ was observed in cells treated with DSF-Cu. We also showed increased ubiquitinated protein levels, as well as apoptosis-related PARP cleavage and morphological changes [181]. Not surprisingly, DSF alone had no obvious effects in cultured cells, which do not contain high levels of copper, but enhanced response was observed in breast cancer cells cultured in copper-enriched medium. Importantly, DSF had no effects on normal breast MCF-10A cells, suggesting a lack of toxicity and a strategy that takes advantage of the increased copper levels observed in human tumor tissues as an anti-tumor mechanism [181].

Our lab has also shown that disulfiram effectively inhibits the proteasome in vivo. We reported significant tumor growth inhibition (74\%) in female athymic nude mice bearing MDA-MB-231 xenografts treated with $50 \mathrm{mg} / \mathrm{kg}$ DSF daily for 30 days. A significant decrease in chymotrypsin-like activity (87\%) and associated accumulation of Bax, p27 and ubiquitinated proteins were apparent and increases in caspase-3 activity and PARP cleavage associated with apoptosis induction were also observed [181].

\section{Clinical trials with DSF}

Importantly, a phase I study investigating the toxicity profile and safety of DSF in combination with copper gluconate (Figure 3) in refractory malignancies with liver metastases (NCT00742911; Huntsman Cancer Institute) is currently recruiting patients. Another phase I/II clinical trial evaluating the effects of DSF in stage IV metastatic melanoma patients has been completed, but results are not yet available (NCT00256230; UC-Irvine). One study is recruiting patients to examine the effects of DSF on PSA levels in recurrent prostate cancer patients (NCT01118741; Johns Hopkins University). Two additional trials are investigating the efficacy of DSF in combination treatments. One is currently re- 
cruiting multiple myeloma patients with one previous treatment and will assess response rate and duration following treatment with DSF and arsenic trioxide (NCT00571116; UC-Irvine). Though results are unavailable, another study, determining the effects of addition of DSF to current chemotherapeutic treatments in patients with non-small cell lung cancer, has been completed (NCT00312819; Hadassah Medical Organization). Overall, these results suggest a potential novel approach for the treatment of human malignancies that utilizes the ability of DSF to chelate cellular copper.

\section{Natural compounds as proteasome inhibitors}

Natural products have recently received considerable attention in the search for more efficacious, less toxic chemotherapeutic agents. Several studies have revealed the potent chemopreventive and therapeutic effects of some natural compounds and as a result, various plant polyphenols have been investigated as potential anti-cancer agents.

\section{Green tea polyphenols}

Derived from the Camellia sinensis plant, tea is the most popular beverage in the world after water. There are many varieties of tea, including black, oolong, and green, all containing many beneficial compounds. The most potent of these are polyphenols, chemical substances characterized by the presence of more than one phenol group per molecule and believed to provide the coloring in many plants [183].

\section{(-)-EGCG in preclinical studies}

The most active polyphenol in tea, (-)-epigallocatechin-3-gallate, or (-)-EGCG (Figure 4), has been shown to possess anticancer activity in several types of cancer [184-186]. The chemopreventive activities of (-)-EGCG are probably due to its effects on signal transduction, inhibition of angiogenesis and stabilization or activation of tumor suppressor genes, such as p53 [187-189]. A recent pilot study investigating the effects of green tea on premalignant prostate lesions revealed that green tea significantly reduced the incidence of prostate cancer development, with only $3 \%$ of patients treated with green tea developing cancer, compared with $30 \%$ of the placebo-treated group [190]. A case-control study in China showed that the risk of prostate cancer is inversely related to frequency, duration, and quantity of green tea consumption [191] and in another study, post-treatment prevention of cancer occurred in patients consuming at least five cups per day, as compared to those consuming fewer than four [192]. Importantly, a recent study in multiple myeloma has revealed a direct interaction between (-)-EGCG and bortezomib (Figures 4 and 1, respectively), inhibiting the efficacy of bortezomib, suggesting that green tea consumption should be limited during bortezomib therapy [193].

Studies in our lab have revealed the potent proteasome-inhibiting ability of (-)-EGCG in vivo and in vitro. (-)-EGCG inhibited the chymotrypsin-like activity in purified $20 \mathrm{~S}$ proteasome $\left(\mathrm{IC}_{50}=86-194\right.$ $\mathrm{nM}$ ), as well as the $26 \mathrm{~S}$ proteasome in Jurkat leukemia, $\mathrm{LNCaP}$ and PC-3 prostate cancer, and MCF-7 breast cancer cell extracts. Associated with this inhibition, increased levels of ubiquitinated proteins, p27, and IkB- $\alpha$ were also observed [194]. Interestingly, the concentrations of (-)-EGCG found in the serum of green tea drinkers are sufficient to cause inhibition of proteasomal activity [194]. We also reported that the ester bond within (-)-EGCG is important to its inhibitory activity [194]. Additionally, although (-)-EGCG is quite potent, it is unstable in neutral or alkaline physiological conditions. Thus, we synthesized several new (-)-EGCG analogs with -OH groups removed from the B-and/or D-rings, as well as their acetate-protected prodrugs (Figure 4), to discover more stable polyphenol proteasome inhibitors. We observed that decreasing the number of $-\mathrm{OH}$ groups from the $\mathrm{B}$ - or D-ring resulted in decreased proteasome inhibitory activity in vitro, but the protected prodrugs inhibited CT-like activity by up to $97 \%$ [195], as well as inhibiting proliferation and inducing apoptosis more potently than (-)EGCG in several cancer cell lines [196]. Conversion to and accumulation of (-)-EGCG also occurred in Pro-EGCG (Figure 4) treated cells [197], and this conversion was confirmed in Jurkat leukemia cells by HPLC analysis [197]. Treatment of mice bearing MDA-MB-231 xenografts with Pro-EGCG resulted 
in more significant suppression of tumor growth, proteasome inhibition, and induction of apoptosis as compared with (-)-EGCG treatment [197]. Thus, Pro-EGCG increases bioavailability, stability, and anticancer efficacy of (-)-EGCG in human breast cancer cells and tumors, suggesting that Pro-EGCG may be a promising agent for the prevention and treatment of cancer.

Our lab has also investigated the effects of methylation on (-)-EGCG, and based on a case-control study suggesting decreased cancer-protection by methylated polyphenols, we hypothesized that methylation would decrease proteasome-inhibition by green tea polyphenols. We synthesized and tested methylated (-)-EGCG and (-)-ECG analogs that can be found in vivo [198]. Adding one methyl group resulted in decreased proteasome inhibition, and inhibitory strength further decreased with the addition of more methyl groups. Jurkat T cells were also treated with methylated peracetate-protected analogs, and the effects were similar to those in purified 20S proteasome; the more highly methylated analogs were less effective [198]. Therefore, proteasome inhibition mediated by green tea polyphenols is suppressed by methylation, ultimately reducing the cancer-preventive effects of these tea polyphenols.

\section{(-)-EGCG in clinical trials}

Some phase I and II clinical trials using (-)-EGCG (Figure 4) and other green tea polyphenols have been completed. One phase I study investigated the optimal dose and tolerability of (-)-EGCG in chronic lymphocytic leukemia (CLL) patients [199]. Thirty-three previously untreated, asymptomatic CLL patients were given Polyphenon E (doses $=400-2000 \mathrm{mg}$ ) and observed for maximum tolerated dose and adverse effects. Maximum tolerated dose was not achieved and only two patients experienced dose limiting toxicities including dysphagia and abdominal discomfort (distention, nausea, flatulence). Other adverse effects were mild and considered non-dose limiting [199]. Only one patient reached partial response (PR), but other clinical effects were observed, including 11 patients (33\%) with sustained $\geq 20 \%$ reduction in absolute lymphocyte count (ALC) and in 12 patients with palpable adenopathy, 11 experienced at least 50\% reduction after (-)-EGCG treatment. This study showed that (-)-EGCG is tolerable and can induce reduction of ALC in patients with CLL, and resulted in a phase II study that began in November 2007 [199]. Another phase I study evaluated the effects of (-)-EGCG supplementation on serum levels of prostate cancer biomoarkers [200]. Twenty-six patients scheduled for radical prostatectomy after positive prostate biopsies took Polyphenon E (containing $800 \mathrm{mg}$ (-)-EGCG) daily until time of surgery. Serum samples taken prior to Polyphenon E treatment and on the day of prostatectomy were tested by ELISA for hepatocyte growth factor (HGF), vascular endothelial growth factor<smiles>O=C(O[C@H]1Cc2c(O)cc(O)cc2O[C@H]1c1cc(O)c(O)c(O)c1)c1cc(O)c(O)c(O)c1</smiles>

(-)-EGCG<smiles>COc1cc(OC(C)=O)cc(OC(C)=O)c1OC(C)=O</smiles>

Pro-(-)-EGCG<smiles>O=c1cc(-c2ccc(O)cc2)oc2cc(O)cc(O)c12</smiles>

Apigenin

Figure 4. Structures of natural compounds used as proteasome inhibitors: Green tea polyphenol (-)-epigallocatechin gallate or (-)-EGCG, its more potent prodrug Pro-EGCG, and the dietary flavonoid apigenin 
(VEGF), insulin-like growth factor (IGF)-I, IGF binding protein-3 (IGFBP-3), and prostate-specific antigen (PSA) [200]. Cancer-associated fibroblasts were also treated with (-)-EGCG and analyzed for protein and mRNA levels of HGF and VEGF and liver function enzymes were monitored to measure toxicity. All prostate cancer-associated biomarkers decreased significantly after treatment with no elevation of liver function enzymes. Protein and mRNA levels of HGF and VEGF in cancer-associated fibroblasts also decreased. Together, these results indicate that even short-term (-)-EGCG treatment may be beneficial in the treatment or prevention of prostate cancer [200].

To study the bioavailability and metabolism of green tea polyphenols in prostate tissue, a clinical trial of 17 men with localized prostate cancer was completed. Eight patients drank six cups of green tea daily for three to six weeks prior to radical prostatectomy, while the remaining nine patients drank water [201]. Prostate tissue was analyzed by HPLC, identifying 4"-O-methyl EGCG (4"-MeEGCG) and EGCG in comparable amounts and (-)-epicatechin-3-gallate in lower amounts in men consuming green tea $(38.9 \pm 19.5,42.1 \pm 32.4$, and $17.8 \pm 10.1 \mathrm{pmol} / \mathrm{g}$ tissue, respectively) and no polyphenols were observed in the tissues of men consuming water [201]. Interestingly, in the urine of patients who consumed green tea, 50-60\% of both primary polyphenols [(-)-epigallocatechin and (-)-epicatechin] existed in methylated form. Additionally, LNCaP cells treated with (-)-EGCG were able to methylate (-)-EGCG to 4"-MeEGCG, a form that is much less potent at inhibiting proliferation and inducing apoptosis than its unmethylated form [201]. These data show that following brief green tea treatment, both methylated and unmethylated EGCG are detectable in prostate tissue and that methylation status may affect the activity of (-)-EGCG.

In addition to the completed clinical trials, a number of phase I and II trials investigating the effects of (-)-EGCG are currently recruiting patients or have begun and are ongoing. Some of these studies are investigating the effects of (-)-EGCG treatment on various types of cancer, including nonmetastatic bladder, breast, cervical, colorectal, prostate, non-small cell lung and uterine carcinomas as well as multiple myeloma. Two other studies are evaluating the effects of (-)-EGCG in combination with EGFR-inhibitor erlotinib in patients with non-small cell lung cancer and premalignant lesions of the head and neck. Finally, still others are examining the preventive effects of (-)-EGCG in patients at risk for cervical, esophageal and lung cancers. The preclinical and clinical data, as well as the large number of recruiting/ongoing clinical trials, clearly suggest a great potential for (-)-EGCG as a chemopreventive and therapeutic agent.

\section{Apigenin}

Apigenin (5,7,4-trihydroxyflavone; Figure 4), a dietary flavonoid found in a variety of natural products including celery seed, chamomile flowers, grapes, and parsley [202-205] has also been shown to possess antioxidant, antimutagenic and chemopreventive properties. Although the mechanism is not fully understood, chemoprevention by apigenin has been reported in several cancers such as cervical [206], lung [207], prostate [208] and skin [209].

\section{Preclinical studies of apigenin}

Studies in our lab have shown that the carybonyl carbon (C4 position) of apigenin (Figure 4) could bind to the $\beta 5$ subunit in an orientation suitable for nucelophilic attack by the N-terminal Thr1 [210]. We reported that apigenin potently inhibits chymotrypsin-like activity in purified $20 \mathrm{~S}$ proteasome $\left(\mathrm{IC}_{50}=1.8-2.3 \mu \mathrm{M}\right)$ and intact $26 \mathrm{~S}$ proteasome in Jurkat leukemia cell lysates $(1-10 \mu \mathrm{M})$ [210], but not in immortalized, non-transformed natural killer cells, suggesting that apigenin exerts its activity with little to no toxicity in healthy cells [210]. We also observed proteasome inhibition-associated accumulation of ubiquitin-tagged proteins as well as apoptosis-associated morphological changes, caspase-3/-7 activation and PARP cleavage. Similar proteasome inhibition and apoptosis induction were observed in breast cancer MBA-MD-231 cells and tumors (up to $40 \%$ inhibition at highest dose) treated with apigenin [211]. Treatment of female nude mice bearing MDA-MB-231 breast cancer xenografts with 
apigenin at two different doses $(25 \mu \mathrm{M}$ and $50 \mu \mathrm{M})$ resulted in $43 \%$ tumor growth inhibition following treatment with the higher dose and importantly, no significant changes in body weight were observed between treatment groups, indicating the low toxicity of this compound [211].

\section{Clinical trials of apigenin}

Results of preclinical studies have led to some clinical trials examining the efficacy of apigenin (Figure 4 ) in human patients. One prospective study investigated the association between flavonol and flavonoid (including apigenin) consumption in the diet and cancer risk [212]. Food-intake questionnaires were analyzed to assess the intake of flavonols/flavonoids in 3234 female cancer patients identified during 11.5 year follow-ups. Unfortunately, no significant associations were observed, indicating that the flavonols/flavonoids tested have little preventive activity [212].

The results of another prospective study were more promising, suggesting a possible role for dietary intake of flavonoids like apigenin in reducing the risk of colorectal cancer [213]. In this study of $87 \mathrm{pa}-$ tients, 36 had resected colon cancer and 51 had undergone polypectomy. Participants were divided into two groups with one receiving a flavonoid mixture [20 mg apigenin $+20 \mathrm{mg}(-)$-EGCG] and the other serving as a matched control group [213]. While none of the patients with resected colon cancer treated with flavonoid mixture $(n=14)$ developed recurrence and only one developed adenoma, of the 15 untreated controls, recurrence occurred in three (20\%) and adenoma in four (27\%). Overall combined recurrence rates were $7 \%(1 / 14)$ and $47 \%(7 / 15)$ in treated and untreated patients, respectively [213]. The results of clinical studies clearly show that further investigation into the preventive and therapeutic effects of apigenin are necessary before any concrete conclusions are reached.

\section{Targeting the upstream factors E1, E2 and E3}

While targeting the catalytic $20 \mathrm{~S}$ core has received considerable attention in the field of drug development, there are other factors in the ubiquitin-proteasome pathway, such as the upstream E1, E2 and E3 enzymes involved in ubiquitin conjugation. In fact, inhibitors of each of these enzymes have been identified and investigated in the preclinical setting. While it was initially believed that inhibiting the ubiquitin E1 would be lethal, the identification of two natural E1 inhibitors has suggested that this may indeed be a viable strategy for the treatment of human cancers. Panepophenanthrin and himeic acid (Figure 5) have both been shown to specifically inhibit the formation of E1-ubiquitin thioester intermediates, with no activity toward the SUMO-1 E1 protein [214,215]. Additionally, a synthetic pyrazone derivative, PYR-41 (Figure 5), with E1-inhibitory activity has been developed that prevents degradation of proteins as well as cytokine-mediated activation of NF- $\mathrm{kB}$, and activates p53 to cause cell death [216].

Importantly, inhibition of the E2 enzymes has also been explored, following the observation that functional knockdown of the E2 Ubc13 resulted in increased p53 activity [217]. Reports have shown that a natural compound, leucettamol A (Figure 5), is able to inhibit the interaction of the E2 Ubc13 with the inactive conjugating enzyme variant Uev1 A, which is required for efficient poly-ubiquitin chain formation [218].

Inhibition of ubiquitin E3 ligases may be one of the more widely researched and successful strategies for targeting upstream ubiquitin-proteasome pathway factors, probably due in part to their role in identifying target proteins for ubiquitination. The E3 family is divided into three classes, RING, HECT and U-box, based on domain structure and mechanisms of target recognition. Because it is frequently overexpressed in human cancers, the p53-specific RING-type E3 MDM2/HDM2 is a popular target for inhibition, which may lead to reactivation of $\mathrm{p} 53$ and resultant apoptosis [219]. For example, the MDM2 small molecule inhibitor nutlin-3 (Figure 5) suppresses tumor progression in mouse xenograft models [220], suggesting that MDM2 is a promising target. More recently, the combination of nutlin-3 with bor- 


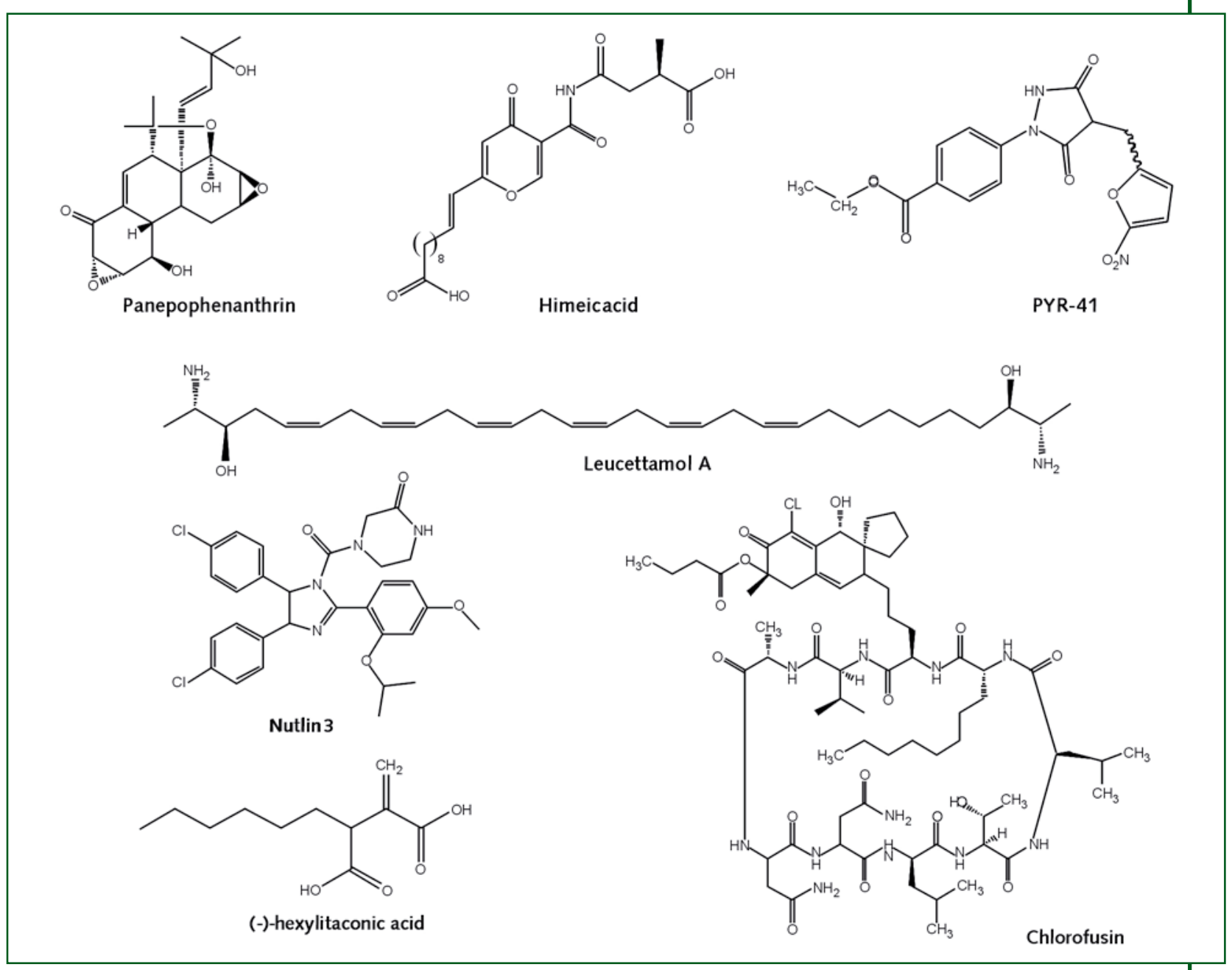

Figure 5. Structures of inhibitors of upstream factors of the ubiquitin-proteasome pathway. E1 inhibitors: panepophenanthrin, himeic acid and PYR-41; E2 inhibitor: leucettamol A; E3 inhibitors: nutlin-3, (-)-hexylitaconic acid and chlorofusin

tezomib was shown to result in additive and synergistic cytotoxic effects in bortezomib-sensitive multiple myeloma and in epithelial carcinoma cells, respectively [221]. In addition, some natural products, such as chlorofusin and (-)-hexylitaconic acid (Figure 5), have been identified that inhibit the interaction between MDM2 and p53 [222-225]. Moreover, disulfiram and its derivatives were able to inhibit zinc finger- and RING-finger-containing ubiquitin E3 ligases [226]. Thus, inhibition of ubiquitination is a very viable strategy that should be further investigated for the treatment of human cancers.

\section{Targeting the 195 regulatory subunit}

The success achieved with inhibitors of the $20 \mathrm{~S}$ catalytic core suggests that inhibition of proteasomal regulators may also be very promising, as this inhibition should only hinder some proteasomal functions. Indeed, the ATPase subunits contained within the base of the $19 \mathrm{~S}$ regulatory cap have proven good drug targets. After screening of a library of purine analog-capped peptoids, RIP-1 (Regulatory Particle Inhibitor Peptoid-1; Figure 6) was identified as an inhibitor of protein unfolding through targeting of the ATPase Rpt4 [227, 228]. Ubiquitin-chain receptors have also been investigated as putative 


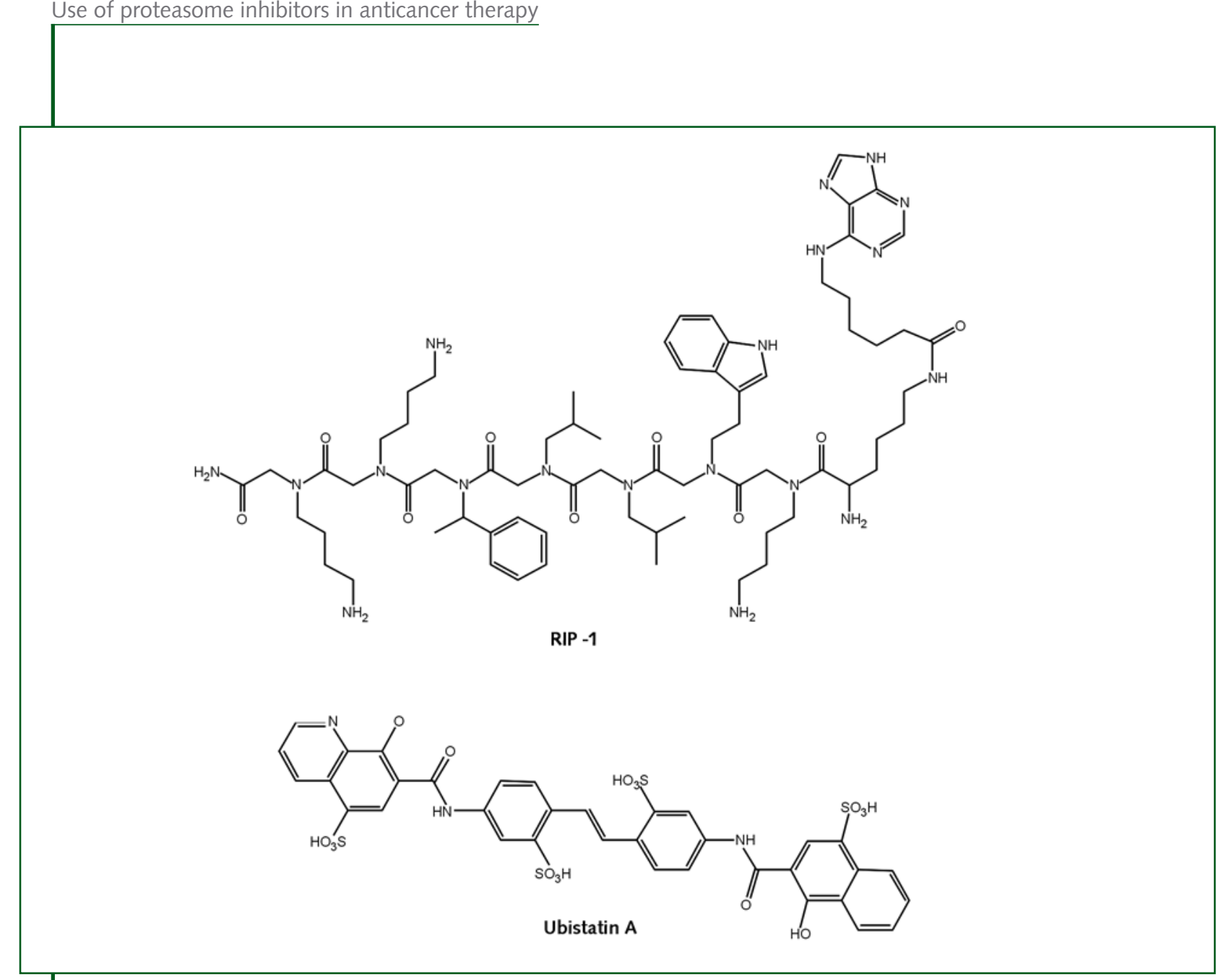

Figure 6. Structures of 195 regulatory subunit Inhibitors RIP-1 and ubistatin A

targets and reports have indicated that ubistatin A (Figure 6) blocks recruitment of ubquitinated proteins to the 26S proteasome by binding the ubiquitin chains, ultimately suppressing proteasome-mediated proteolysis [229]. Clearly, factors that regulate the 20S catalytic core are good drug targets and further investigation into this strategy would be very worthwhile.

\section{Conclusions and future directions}

The importance of the ubiquitin-proteasome pathway to cellular homeostasis as well as the discovery that malignant cells exhibit increased proteasome activity have prompted investigation into the possibility that this pathway may be a promising target for cancer therapeutics. Current standard of care for most cancers include surgery, chemotherapy and radiotherapy, and targeting the ubiquitin-proteasome pathway may reduce the toxicity associated with current chemotherapeutics or radiation. The clinical use of proteasome inhibitors has been validated by the FDA approval of bortezomib for the treatment of multiple myeloma and mantle cell lymphoma. However, some toxicity and resistance has been associated with bortezomib treatment, stimulating the search for less toxic proteasome inhibitors. This search has resulted in many preclinical and clinical studies investigating the efficacy of drugs currently approved for other diseases as well as natural compounds, which should display lower toxicity and resistance than bortezomib. Disulfiram, an anti-alcoholism drug approved by the FDA, can chelate intracellular copper, resulting in proteasome inhibition and associated cellular death. The success of disulfiram in vitro and in vivo 
has also led to clinical trials investigating disulfiram both alone and in combination. Some natural compounds including the green tea polyphenol (-)-EGCG and the flavonoid apigenin are also proven proteasome inhibitors. These compounds potently induce apoptosis in several cancer types in vitro and in vivo and have also been shown to possess chemopreventive activities. Clinical trials using (-)-EGCG have yielded very promising results, while those using apigenin have been inconsistent and further studies are necessary. Using natural compounds to sensitize resistant tumors to chemotherapy/radiotherapy has been well documented and the use of novel natural compounds to sensitize bortezomibresistant tumors is an important field of research in which we and many others are involved.

The overwhelmingly positive results achieved with proteasome inhibitors clearly demonstrate that targeting the ubiquitin-proteasome pathway is a viable strategy for anti-cancer treatment and prevention. The use of these compounds in combination with current chempotherapeutics may also be very effective, especially against drug-resistant tumors. Other promising directions include inhibitors against enzymes involved in ubiquitin conjugation and ligation, which would act early in the ubiquitin-proteasome pathway (Figure 1) and could specifically target many cancer-related proteins, as well as $19 \mathrm{~S}$ regulators of the $20 \mathrm{~S}$ core, which would block entry of proteins into the core for degradation. Indeed, several potential upstream inhibitors have already been identified. Additionally, the various roles for ubiquitinlike proteins such as SUMO and NEDD8 indicate that inhibition of these proteins may also be a viable strategy. Thus, targeting the ubiquitin-proteasome pathway, through both direct inhibition of the $20 \mathrm{~S}$ proteasome and inhibition of necessary ligases and regulatory proteins, remains a promising strategy in the treatment of human cancers.

\section{Acknowledgements}

This work was partially supported by grants from the National Cancer Institute (1R01CA120009, 3R01CA120009-04S1 and 5R01CA127258-05, to $\mathrm{QPD}$ ).

\section{Questions for further research}

Further clinical studies are necessary to prove the chemosensitizing properties of natural compounds and copper-binding compounds. More importantly, phase III clinical trials must be completed in order for some of these compounds to achieve widespread clinical use.

The review in brief

Clinical Problem The current standard of care for cancer treatment includes surgery, chemotherapy and radiotherapy. These treatments are often accompanied by severe side effects and resistance and recurrence rate is generally high.

Outcomes Bortezomib, disulfiram, (-)-EGCG and apigenin are potent proteasome inhibitors and apoptosis inducers as well as chemosensitizers in cancers.

Clinical Relevance Targeting the tumor ubiquitin-proteasome pathway is a promising strategy in anticancer therapy. Using existing drugs and natural compounds may help reduce toxicity and resistance associated with current chemotherapies.

\section{References}

1. Ciehanover A, Hod Y, Hershko A. A heat-stable polypeptide component of an ATP-dependent proteolytic system from reticulocytes. Biochem Biophys Res Commun 1978; 81: 1100-5 
2. Hershko A, Ciechanover A, Heller H, Haas AL, Rose IA. Proposed role of ATP in protein breakdown: conjugation of protein with multiple chains of the polypeptide of ATP-dependent proteolysis. Proc Natl Acad Sci U S A 1980; 77: 1783-6

3. Nalepa G, Rolfe M, Harper JW. Drug discovery in the ubiquitin-proteasome system. Nat Rev Drug Discov 2006; 5: 596-613

4. Smith L, Lind MJ, Drew PJ, Cawkwell L. The putative roles of the ubiquitin/proteasome pathway in resistance to anticancer therapy. Eur J Cancer 2007; 43: 2330-8

5. QP Dou, Li B. Proteasome inhibitors as potential novel anticancer agents. Drug Resist Updat 1999; 2: $215-23$

6. Li B, Dou QP. Bax degradation by the ubiquitin/proteasome-dependent pathway: involvement in tumor survival and progression. Proc Natl Acad Sci U S A 2000; 97: 3850-5

7. Loda M, Cukor B, Tam SW, Lavin P, Fiorentino M, Draetta GF, et al. Increased proteasome-dependent degradation of the cyclin-dependent kinase inhibitor p27 in aggressive colorectal carcinomas. Nat Med 1997; 3: 231-4

8. Kumatori A, Tanaka K, Inamura N, Sone S, Ogura T, Matsumoto T, et al. Abnormally high expression of proteasomes in human leukemic cells. Proc Natl Acad Sci U S A 1990; 87: 7071-5

9. An B, Goldfarb RH, Siman R, Dou QP. Novel dipeptidyl proteasome inhibitors overcome Bcl2 protective function and selectively accumulate the cyclin-dependent kinase inhibitor p27 and induce apoptosis in transformed, but not normal, human fibroblasts. Cell Death Differ 1998; 5: 1062-75

10. Lopes UG, Erhardt P, Yao R, Cooper GM. p53-dependent induction of apoptosis by proteasome inhibitors. J Biol Chem 1997; 272: 12893-6

11. Orlowski RZ, Kuhn DJ. Proteasome inhibitors in cancer therapy: lessons from the first decade. Clin Cancer Res 2008; 14: 1649-57

12. Ciechanover A. The ubiquitin-proteasome pathway: on protein death and cell life. EMBO J 1998; 17: 7151-60

13. Rivett AJ. Intracellular distribution of proteasomes. Curr Opin Immunol 1998; 10: 110-4

14. Hirsch, C. and H.L. Ploegh, Intracellular targeting of the proteasome. Trends Cell Biol, 2000. 10(7): 268-72

15. Wojcik, C. and G.N. DeMartino, Intracellular localization of proteasomes. Int J Biochem Cell Biol, 2003. 35(5): 579-89

16. Adams, J, The proteasome: a suitable antineoplastic target. Nat Rev Cancer, 2004. 4(5): 349-60

17. Peters JM, Cejka Z, Harris JR, Kleinschmidt JA, Baumeister W. Structural features of the $26 \mathrm{~S}$ proteasome complex. J Mol Biol 1993; 234: 932-7

18. Baumeister W, Walz J, Zühl F, Seemüller E. The proteasome: paradigm of a self-compartmentalizing protease. Cell 1998; 92: 367-80

19. Groll M, Ditzel L, Löwe J, Stock D, Bochtler M, Bartunik HD, Huber R. Structure of 20S proteasome from yeast at 2.4 A resolution. Nature 1997; 386: 463-71

20. Groll M, Heinemeyer W, Jäger S, Ullrich T, Bochtler M, Wolf DH, et al. The catalytic sites of 20S proteasomes and their role in subunit maturation: a mutational and crystallographic study. Proc Natl Acad Sci U S A 1999; 96: 10976-83

21. DeMartino GN, Slaughter CA. The proteasome, a novel protease regulated by multiple mechanisms. J Biol Chem 1999; 274: 22123-6

22. Goldberg AL, Cascio P, Saric T, Rock KL. The importance of the proteasome and subsequent proteolytic steps in the generation of antigenic peptides. Mol Immunol 2002; 39: 147-64

23. Coux O, Tanaka K, Goldberg AL. Structure and functions of the $20 \mathrm{~S}$ and $26 \mathrm{~S}$ proteasomes. Annu Rev Biochem 1996; 65: 801-47

24. Nandi D, Tahiliani P, Kumar A, Chandu D. The ubiquitin-proteasome system. J Biosci 2006; 31: 137-55 
25. Nickell S, Beck F, Scheres SH, Korinek A, Förster F, Lasker K, et al. Insights into the molecular architecture of the 26S proteasome. Proc Natl Acad Sci U S A 2009; 106: 11943-7

26. da Fonseca PC, Morris EP. Structure of the human 26S proteasome: subunit radial displacements open the gate into the proteolytic core. J Biol Chem 2008; 283: 23305-14

27. Hartmann-Petersen R, Tanaka K, Hendil KB. Quaternary structure of the ATPase complex of human 26 S proteasomes determined by chemical cross-linking. Arch Biochem Biophys 2001; 386: 89-94

28. Fu H, Doelling JH, Rubin DM, Vierstra RD. Structural and functional analysis of the six regulatory particle triple-A ATPase subunits from the Arabidopsis 26S proteasome. Plant J 1999; 18: 529-39

29. Rubin DM, Glickman MH, Larsen CN, Dhruvakumar S, Finley D. Active site mutants in the six regulatory particle ATPases reveal multiple roles for ATP in the proteasome. EMBO J 1998; 17: 4909-19

30. Finley D. Recognition and processing of ubiquitin-protein conjugates by the proteasome. Annu Rev Biochem 2009; 78: 477-513

31. Deveraux Q, Ustrell V, Pickart C, Rechsteiner M. A 26 S protease subunit that binds ubiquitin conjugates. J Biol Chem 1994; 269: 7059-61

32. Hamazaki J, Iemura S, Natsume T, Yashiroda H, Tanaka K, Murata S. A novel proteasome interacting protein recruits the deubiquitinating enzyme $\mathrm{UCH} 37$ to $26 \mathrm{~S}$ proteasomes. $E M B O J, 2006 ; 25$ : 4524-36

33. Qiu XB, Ouyang SY, Li CJ, Miao S, Wang L, Goldberg AL. hRpn13/ADRM1/GP110 is a novel proteasome subunit that binds the deubiquitinating enzyme, UCH37. EMBO J 2006; 25: 5742-53

34. Yao T, Song L, Xu W, DeMartino GN, Florens L, Swanson SK, et al. Proteasome recruitment and activation of the Uch37 deubiquitinating enzyme by Adrm1. Nat Cell Biol 2006; 8: 994-1002

35. Amerik AY, Hochstrasser M. Mechanism and function of deubiquitinating enzymes. Biochim Biophys Acta 2004; 1695: 189-207

36. Jariel-Encontre I, Bossis G, Piechaczyk M. Ubiquitin-independent degradation of proteins by the proteasome. Biochim Biophys Acta 2008; 1786: 153-77

37. Hoyt MA, Zhang M, Coffino P. Ubiquitin-independent mechanisms of mouse ornithine decarboxylase degradation are conserved between mammalian and fungal cells. J Biol Chem 2003; 278: 12135-43

38. Hoyt MA, Coffino P. Ubiquitin-free routes into the proteasome. Cell Mol Life Sci 2004; 61: 1596600

39. Adams J. The proteasome: structure, function, and role in the cell. Cancer Treat Rev 2003; 29(Suppl 1): 3-9

40. Ciechanover A, Orian A, Schwartz AL. Ubiquitin-mediated proteolysis: biological regulation via destruction. Bioessays 2000; 22: 442-51

41. Ciechanover A. The ubiquitin proteolytic system: from a vague idea, through basic mechanisms, and onto human diseases and drug targeting. Neurology 2006; 66(2 Suppl 1): S7-19

42. Adams J. The development of proteasome inhibitors as anticancer drugs. Cancer Cell 2004; 5: 417 21

43. Krogan NJ, Lam MH, Fillingham J, Keogh MC, Gebbia M, Li J, et al. Proteasome involvement in the repair of DNA double-strand breaks. Mol Cell 2004; 16: 1027-34

44. Baker SP, Grant PA. The proteasome: not just degrading anymore. Cell, 2005; 123: 361-3

45. Collins, GA, Tansey WP. The proteasome: a utility tool for transcription? Curr Opin Genet Dev 2006; 16: 197-202

46. Ferdous A, Gonzalez F, Sun L, Kodadek T, Johnston SA. The 19S regulatory particle of the proteasome is required for efficient transcription elongation by RNA polymerase II. Mol Cell 2001; 7: 981-91 
47. Chen ZJ, Sun LJ. Nonproteolytic functions of ubiquitin in cell signaling. Mol Cell 2009; 33: 275-86

48. Gill G. SUMO and ubiquitin in the nucleus: different functions, similar mechanisms? Genes Dev 2004; 18: 2046-59

49. Tatham MH, Jaffray E, Vaughan OA, Desterro JM, Botting CH, Naismith JH, Hay RT. Polymeric chains of SUMO-2 and SUMO-3 are conjugated to protein substrates by SAE1/SAE2 and Ubc9. J Biol Chem 2001; 276: 35368-74

50. Bylebyl GR, Belichenko I, Johnson ES. The SUMO isopeptidase Ulp2 prevents accumulation of SUMO chains in yeast. J Biol Chem 2003; 278: 44113-20

51. Bayer P, Arndt A, Metzger S, Mahajan R, Melchior F, Jaenicke R, Becker J. Structure determination of the small ubiquitin-related modifier SUMO-1. J Mol Biol 1998; 280: 275-86

52. Kamitani T, Nguyen HP, Yeh ET. Preferential modification of nuclear proteins by a novel ubiquitin-like molecule. J Biol Chem 1997; 272: 14001-4

53. Kamitani T, Kito K, Nguyen HP, Fukuda-Kamitani T, Yeh ET. Characterization of a second member of the sentrin family of ubiquitin-like proteins. J Biol Chem 1998; 273: 11349-53

54. Johnson ES, Blobel G. Ubc9p is the conjugating enzyme for the ubiquitin-like protein Smt3p. J Biol Chem 1997; 272: 26799-802

55. Li SJ, Hochstrasser M. A new protease required for cell-cycle progression in yeast. Nature 1999; 398: 246-51

56. Johnson ES, Schwienhorst I, Dohmen RJ, Blobel G. The ubiquitin-like protein Smt3p is activated for conjugation to other proteins by an Aos1p/Uba2p heterodimer. EMBO J 1997; 16: 5509-19

57. Desterro JM, Rodriguez MS, Kemp GD, Hay RT. Identification of the enzyme required for activation of the small ubiquitin-like protein SUMO-1. J Biol Chem 1999; 274: 10618-24

58. Gong L, Li B, Millas S, Yeh ET. Molecular cloning and characterization of human AOS1 and UBA2, components of the sentrin-activating enzyme complex. FEBS Lett 1999; 448: 185-9

59. Okuma T, Honda R, Ichikawa G, Tsumagari N, Yasuda H. In vitro SUMO-1 modification requires two enzymatic steps, E1 and E2. Biochem Biophys Res Commun 1999; 254: 693-8

60. Desterro JM, Thomson J, Hay RT. Ubch9 conjugates SUMO but not ubiquitin. FEBS Lett, 1997; 417: 297-300

61. Gong L, Kamitani T, Fujise K, Caskey LS, Yeh ET. Preferential interaction of sentrin with a ubiquitin-conjugating enzyme, Ubc9. J Biol Chem 1997; 272: 28198-201

62. Lee GW, Melchior F, Matunis MJ, Mahajan R, Tian Q, Anderson P. Modification of Ran GTPaseactivating protein by the small ubiquitin-related modifier SUMO-1 requires Ubc9, an E2-type ubiquitin-conjugating enzyme homologue. J Biol Chem, 1998; 273: 6503-7

63. Saitoh H, Sparrow DB, Shiomi T, Pu RT, Nishimoto T, Mohun TJ, Dasso M. Ubc9p and the conjugation of SUMO-1 to RanGAP1 and RanBP2. Curr Biol 1998; 8: 121-4

64. Schwarz SE, Matuschewski K, Liakopoulos D, Scheffner M, Jentsch S. The ubiquitin-like proteins SMT3 and SUMO-1 are conjugated by the UBC9 E2 enzyme. Proc Natl Acad Sci U S A 1998; 95: 560-4

65. Desterro JM, Rodriguez MS, Hay RT. SUMO-1 modification of IkappaBalpha inhibits NF-kappaB activation. Mol Cell 1998; 2: 233-9

66. Wada H, Kito K, Caskey LS, Yeh ET, Kamitani T, et al. Cleavage of the C-terminus of NEDD8 by UCH-L3. Biochem Biophys Res Commun 1998; 251: 688-92

67. Kipreos ET, Lander LE, Wing JP, He WW, Hedgecock EM. cul-1 is required for cell cycle exit in C. elegans and identifies a novel gene family. Cell 1996; 85: 829-39

68. Osaka F, Kawasaki H, Aida N, Saeki M, Chiba T, Kawashima S, Tanaka K, Kato S. A new NEDD8ligating system for cullin-4A. Genes Dev 1998; 12: 2263-8

69. Hori T, Osaka F, Chiba T, Miyamoto C, Okabayashi K, Shimbara N, Kato S, Tanaka K. Covalent modification of all members of human cullin family proteins by NEDD8. Oncogene 1999; 18: 6829-34 
70. Wada H, Yeh ET, Kamitani T. Identification of NEDD8-conjugation site in human cullin-2. Biochem Biophys Res Commun 1999; 257: 100-5

71. Gong L, Yeh ET. Identification of the activating and conjugating enzymes of the NEDD8 conjugation pathway. J Biol Chem 1999; 274: 12036-42

72. Pozo JC, Timpte C, Tan S, Callis J, Estelle M. The ubiquitin-related protein RUB1 and auxin response in Arabidopsis. Science 1998; 280: 1760-3

73. Lammer D, Mathias N, Laplaza JM, Jiang W, Liu Y, Callis J, Goebl M, Estelle M. Modification of yeast Cdc53p by the ubiquitin-related protein rublp affects function of the SCFCdc4 complex. Genes Dev 1998; 12: 914-26

74. Liakopoulos D, Doenges G, Matuschewski K, Jentsch S. A novel protein modification pathway related to the ubiquitin system. EMBO J 1998; 17: 2208-14

75. Ledl A, Schmidt D, Muller S. Viral oncoproteins E1A and E7 and cellular LxCxE proteins repress SUMO modification of the retinoblastoma tumor suppressor. Oncogene 2005; 24: 3810-8

76. Rizos H, Woodruff S, Kefford RF. p14ARF interacts with the SUMO-conjugating enzyme Ubc9 and promotes the sumoylation of its binding partners. Cell Cycle, 2005; 4: 597-603

77. Wang, L, Banerjee S. Differential PIAS3 expression in human malignancy. Oncol Rep 2004; 11: 1319-24

78. Lee K. Transactivation of peroxisome proliferator-activated receptor alpha by green tea extracts. $J$ Vet Sci 2004; 5: 325-30

79. Mo YY, Yu Y, Theodosiou E, Ee PL, Beck WT. A role for Ubc9 in tumorigenesis. Oncogene 2005; 24: $2677-83$

80. Meehan KL, Holland JW, Dawkins HJ. Proteomic analysis of normal and malignant prostate tissue to identify novel proteins lost in cancer. Prostate 2002; 50: 54-63

81. Mo YY, Moschos SJ. Targeting Ubc9 for cancer therapy. Expert Opin Ther Targets 2005; 9: 1203-16

82. Adams J, Palombella VJ, Sausville EA, Johnson J, Destree A, Lazarus DD, et al. Proteasome inhibitors: a novel class of potent and effective antitumor agents. Cancer Res 1999; 59: 2615-22

83. Frankel A, Man S, Elliott P, Adams J, Kerbel RS. Lack of multicellular drug resistance observed in human ovarian and prostate carcinoma treated with the proteasome inhibitor PS-341. Clin Cancer Res 2000; 6: 3719-28

84. Hideshima T, Richardson P, Chauhan D, Palombella VJ, Elliott PJ, Adams J, Anderson KC. The proteasome inhibitor PS-341 inhibits growth, induces apoptosis, and overcomes drug resistance in human multiple myeloma cells. Cancer Res 2001; 61: 3071-6

85. Supko JG, Lynch TJ, et al. Pharmacokinetics of irinotecan and the proteasome inhibitor bortezomib in adult patients with solid malignancies (abstract/poster 544). Proc Am Soc Clin Oncol 2003; 136

86. Appleman LJ, Ryan DP, Clark JW, Eder JP, Fishman M, Cusack JC, et al. Phase I dose escalation study of bortezomib and gemcitabine safety and tolerability in patients with advanced solid tumors (abstract 839). Proc Am Soc Clin Oncol 2003; 209

87. Nix D, M.M, Pligavko C, et al., Pharmacokinetics of the proteasome inhibitor bortezomib (Velcade) in male cynomolgus monkeys (abstract C245), in American Association for Cancer Research-National Cancer Institute-European Organization for Research and Treatment of Cancer Molecular Targets and Cancer Therapeutics Discovery, Biology, and Clinical Applications meeting. 2003: Boston

88. Nix D PR, Wehrman T, et al. Tissue distribution and mass balance of bortezomib (Velcade) in non-human primates (abstract M1336). Salt Lake City: The Annual Meeting of the American Association of Pharmaceutical Scientists, 2003

89. Kane RC, Farrell AT, Sridhara R, Pazdur R. Velcade: U.S. FDA approval for the treatment of multiple myeloma progressing on prior therapy. Oncologist 2003; 8: 508-13

90. Schwartz R, Davidson T. Pharmacology, pharmacokinetics, and practical applications of bortezomib. Oncology (Williston Park) 2004; 18(14 Suppl 11): 14-21 
91. Crawford LJ, Walker B, Ovaa H, Chauhan D, Anderson KC, Morris TC, Irvine AE. Comparative selectivity and specificity of the proteasome inhibitors BzLLLCOCHO, PS-341, and MG-132. Cancer Res 2006; 66: 6379-86

92. Engel RH, Brown JA, Von Roenn JH, O’Regan RM, Bergan R, Badve S, et al. A phase II study of single agent bortezomib in patients with metastatic breast cancer: a single institution experience. Cancer Invest 2007; 25: 733-7

93. Yang CH, Gonzalez-Angulo AM, Reuben JM, Booser DJ, Pusztai L, Krishnamurthy S, et al. Bortezomib (VELCADE) in metastatic breast cancer: pharmacodynamics, biological effects, and prediction of clinical benefits. Ann Oncol 2006; 17: 813-7

94. Berenson JR, Yang HH, Sadler K, Jarutirasarn SG, Vescio RA, Mapes R, et al. Phase I/II trial assessing bortezomib and melphalan combination therapy for the treatment of patients with relapsed or refractory multiple myeloma. J Clin Oncol 2006; 24: 937-44

95. Edelman MJ. The potential role of bortezomib in combination with chemotherapy and radiation in non-small-cell lung cancer. Clin Lung Cancer 2005; 7(Suppl 2): S64-6

96. Russo SM, Tepper JE, Baldwin AS Jr, Liu R, Adams J, Elliott P, et al. Enhancement of radiosensitivity by proteasome inhibition: implications for a role of NF-kappaB. Int J Radiat Oncol Biol Phys 2001; 50: 183-93

97. Messersmith WA, Baker SD, Lassiter L, Sullivan RA, Dinh K, Almuete VI, et al. Phase I trial of bortezomib in combination with docetaxel in patients with advanced solid tumors. Clin Cancer Res 2006; 12: 1270-5

98. Orlowski RZ, Voorhees PM, Garcia RA, Hall MD, Kudrik FJ, Allred T, et al. Phase 1 trial of the proteasome inhibitor bortezomib and pegylated liposomal doxorubicin in patients with advanced hematologic malignancies. Blood 2005; 105: 3058-65

99. Perrone G, Hideshima T, Ikeda H, Okawa Y, Calabrese E, Gorgun G, et al. Ascorbic acid inhibits antitumor activity of bortezomib in vivo. Leukemia 2009; 23: 1679-86

100. Ryan DP, O’Neil BH, Supko JG, Rocha Lima CM, Dees EC, Appleman LJ, et al. A Phase I study of bortezomib plus irinotecan in patients with advanced solid tumors. Cancer 2006; 107: 2688-97

101. Adams J. Preclinical and clinical evaluation of proteasome inhibitor PS-341 for the treatment of cancer. Curr Opin Chem Biol 2002; 6: 493-500

102. Jagannath S, Durie BG, Wolf J, Camacho E, Irwin D, Lutzky J, et al. Bortezomib therapy alone and in combination with dexamethasone for previously untreated symptomatic multiple myeloma. $\mathrm{Br}$ J Haematol 2005; 129: 776-83

103. Kondagunta GV, Drucker B, Schwartz L, Bacik J, Marion S, Russo P, et al. Phase II trial of bortezomib for patients with advanced renal cell carcinoma. J Clin Oncol 2004; 22: 3720-5

104. Richardson, P.G, et al, Bortezomib or high-dose dexamethasone for relapsed multiple myeloma. $N$ Engl J Med 2005; 352: 2487-98

105. Shah, S.A, et al, 26S proteasome inhibition induces apoptosis and limits growth of human pancreatic cancer. J Cell Biochem 2001; 82: 110-22

106. Sunwoo, J.B, et al, Novel proteasome inhibitor PS-341 inhibits activation of nuclear factor-kappa $\mathrm{B}$, cell survival, tumor growth, and angiogenesis in squamous cell carcinoma. Clin Cancer Res, 2001. 7(5): 1419-28

107. Ma, M.H, et al, The proteasome inhibitor PS-341 markedly enhances sensitivity of multiple myeloma tumor cells to chemotherapeutic agents. Clin Cancer Res, 2003. 9(3): 1136-44

108. Berenson, J.R, H.M. Ma, and R. Vescio, The role of nuclear factor-kappaB in the biology and treatment of multiple myeloma. Semin Oncol, 2001. 28(6): 626-33

109. LeBlanc R, Catley LP, Hideshima T, Lentzsch S, Mitsiades CS, Mitsiades N, et al. Proteasome inhibitor PS-341 inhibits human myeloma cell growth in vivo and prolongs survival in a murine model. Cancer Res 2002; 62: 4996-5000 
110. Qin JZ, Ziffra J, Stennett L, Bodner B, Bonish BK, Chaturvedi V, et al. Proteasome inhibitors trigger NOXA-mediated apoptosis in melanoma and myeloma cells. Cancer Res 2005; 65: 6282-93

111. Oda E, Ohki R, Murasawa H, Nemoto J, Shibue T, Yamashita T, et al. Noxa, a BH3-only member of the Bcl-2 family and candidate mediator of p53-induced apoptosis. Science 2000; 288: 1053-8

112. Adams JM, Cory S. The Bcl-2 protein family: arbiters of cell survival. Science 1998; 281: 1322-6

113. Gross A, McDonnell JM, Korsmeyer SJ. BCL-2 family members and the mitochondria in apoptosis. Genes Dev 1999; 13: 1899-911

114. Nikiforov MA, Riblett M, Tang WH, Gratchouck V, Zhuang D, Fernandez Y, et alS. Tumor cellselective regulation of NOXA by c-MYC in response to proteasome inhibition. Proc Natl Acad Sci U S A 2007; 104: 19488-93

115. Caravita T, de Fabritiis P, Palumbo A, Amadori S, Boccadoro M. Bortezomib: efficacy comparisons in solid tumors and hematologic malignancies. Nat Clin Pract Oncol 2006; 3: 374-87

116. Fernández Y, Verhaegen M, Miller TP, Rush JL, Steiner P, Opipari AW Jr, Lowe SW, Soengas MS. Differential regulation of noxa in normal melanocytes and melanoma cells by proteasome inhibition: therapeutic implications. Cancer Res 2005; 65: 6294-304

117. Qin JZ, Xin H, Sitailo LA, Denning MF, Nickoloff BJ. Enhanced killing of melanoma cells by simultaneously targeting Mcl-1 and NOXA. Cancer Res 2006; 66: 9636-45

118. Chauhan D, Anderson KC. Mechanisms of cell death and survival in multiple myeloma (MM): Therapeutic implications. Apoptosis 2003; 8: 337-43

119. Feinman R, Koury J, Thames M, Barlogie B, Epstein J, Siegel DS. Role of NF-kappaB in the rescue of multiple myeloma cells from glucocorticoid-induced apoptosis by bcl-2. Blood 1999; 93: 3044-52

120. Hideshima T, Ikeda H, Chauhan D, Okawa Y, Raje N, Podar K, et al. Bortezomib induces canonical nuclear factor-kappaB activation in multiple myeloma cells. Blood 2009; 114: 1046-52

121. Kukreja A, Hutchinson A, Mazumder A, Vesole D, Angitapalli R, Jagannath S, et al. Bortezomib disrupts tumour-dendritic cell interactions in myeloma and lymphoma: therapeutic implications. Br J Haematol 2007; 136: 106-10

122. Fribley A, Wang CY. Proteasome inhibitor induces apoptosis through induction of endoplasmic reticulum stress. Cancer Biol Ther 2006; 5: 745-8

123. Fribley A, Zeng Q, Wang CY. Proteasome inhibitor PS-341 induces apoptosis through induction of endoplasmic reticulum stress-reactive oxygen species in head and neck squamous cell carcinoma cells. Mol Cell Biol 2004; 24: 9695-704

124. Nawrocki ST, Bruns CJ, Harbison MT, Bold RJ, Gotsch BS, Abbruzzese JL, et al. Effects of the proteasome inhibitor PS-341 on apoptosis and angiogenesis in orthotopic human pancreatic tumor xenografts. Mol Cancer Ther 2002; 1: 1243-53

125. Mitsiades N, Mitsiades CS, Poulaki V, Chauhan D, Fanourakis G, Gu X, et al. Molecular sequelae of proteasome inhibition in human multiple myeloma cells. Proc Natl Acad Sci U S A 2002; 99: 14374-9

126. Strauss SJ, Higginbottom K, Jüliger S, Maharaj L, Allen P, Schenkein D, et al, The proteasome inhibitor bortezomib acts independently of p53 and induces cell death via apoptosis and mitotic catastrophe in B-cell lymphoma cell lines. Cancer Res 2007; 67: 2783-90

127. Lioni M, Noma K, Snyder A, Klein-Szanto A, Diehl JA, Rustgi AK, Herlyn M, Smalley KS. Bortezomib induces apoptosis in esophageal squamous cell carcinoma cells through activation of the p38 mitogen-activated protein kinase pathway. Mol Cancer Ther 2008; 7: 2866-75

128. Orlowski RZ, Stinchcombe TE, Mitchell BS, Shea TC, Baldwin AS, Stahl S, et al, Phase I trial of the proteasome inhibitor PS-341 in patients with refractory hematologic malignancies. J Clin Oncol 2002; 20: 4420-7

129. Papandreou CN, Daliani DD, Nix D, Yang H, Madden T, Wang X, et al. Phase I trial of the proteasome inhibitor bortezomib in patients with advanced solid tumors with observations in androgenindependent prostate cancer. J Clin Oncol 2004; 22: 2108-21 
130. Aghajanian C, Soignet S, Dizon DS, Pien CS, Adams J, Elliott PJ, et al. A phase I trial of the novel proteasome inhibitor PS341 in advanced solid tumor malignancies. Clin Cancer Res 2002; 8: 2505-11

131. Dou QP, Goldfarb RH. Bortezomib (millennium pharmaceuticals). IDrugs 2002; 5: 828-34

132. Kong X, Alvarez-Castelao B, Lin Z, Castaño JG, Caro J. Constitutive/hypoxic degradation of HIFalpha proteins by the proteasome is independent of von Hippel Lindau protein ubiquitylation and the transactivation activity of the protein. J Biol Chem 2007; 282: 15498-505

133. Morris MJ, Kelly WK, Slovin S, Ryan C, Eicher C, Heller G, Scher HI. A phase II trial of bortezomib and prednisone for castration resistant metastatic prostate cancer. J Urol 2007; 178: 2378-83; discussion 2383-4

134. Dreicer R, Petrylak D, Agus D, Webb I, Roth B. Phase I/II study of bortezomib plus docetaxel in patients with advanced androgen-independent prostate cancer. Clin Cancer Res 2007; 13: 1208-15

135. Hainsworth JD, Meluch AA, Spigel DR, Barton J Jr, Simons L, Meng C, Gould B, Greco FA. Weekly docetaxel and bortezomib as first-line treatment for patients with hormone-refractory prostate cancer: a Minnie Pearl Cancer Research Network phase II trial. Clin Genitourin Cancer 2007; 5: 278-83

136. Richardson, P.G, et al, A phase 2 study of bortezomib in relapsed, refractory myeloma. $N$ Engl J Med 2003; 348: 2609-17

137. Jagannath $\mathrm{S}$, et al, A phase 2 study of two doses of bortezomib in relapsed or refractory myeloma. Br J Haematol 2004; 127: 165-72

138. Oakervee HE, Popat R, Curry N, Smith P, Morris C, Drake M, et al. PAD combination therapy (PS341/bortezomib, doxorubicin and dexamethasone) for previously untreated patients with multiple myeloma. Br J Haematol 2005; 129: 755-62

139. Belch A, Kouroukis CT, Crump M, Sehn L, Gascoyne RD, Klasa R, Powers J, Wright J, Eisenhauer EA. A phase II study of bortezomib in mantle cell lymphoma: the National Cancer Institute of Canada Clinical Trials Group trial IND.150. Ann Oncol 2007; 18: 116-21

140. O‘Connor OA, Wright J, Moskowitz C, Muzzy J, MacGregor-Cortelli B, Stubblefield M, et al. Phase II clinical experience with the novel proteasome inhibitor bortezomib in patients with indolent non-Hodgkin's lymphoma and mantle cell lymphoma. J Clin Oncol 2005; 23: 676-84

141. Scagliotti GV, Germonpré P, Bosquée L, Vansteenkiste J, Gervais R, Planchard D, et al. A randomized phase II study of bortezomib and pemetrexed, in combination or alone, in patients with previously treated advanced non-small-cell lung cancer. Lung Cancer 2010; 68: 420-6

142. Richardson PG, Sonneveld P, Schuster MW, Stadtmauer EA, Facon T, Harousseau JL, et al. Reversibility of symptomatic peripheral neuropathy with bortezomib in the phase III APEX trial in relapsed multiple myeloma: impact of a dose-modification guideline. Br J Haematol 2009; 144: 895-903

143. Mikhael JR, Belch AR, Prince HM, Lucio MN, Maiolino A, Corso A, et al. High response rate to bortezomib with or without dexamethasone in patients with relapsed or refractory multiple myeloma: results of a global phase 3b expanded access program. Br J Haematol 2009; 144: 169-75

144. Fonseca R, Rajkumar SV. Consolidation therapy with bortezomib/lenalidomide/ dexamethasone versus bortezomib/dexamethasone after a dexamethasone-based induction regimen in patients with multiple myeloma: a randomized phase III trial. Clin Lymphoma Myeloma 2008; 8: 315-7

145. San Miguel JF, Schlag R, Khuageva NK, Dimopoulos MA, Shpilberg O, Kropff M, Bortezomib plus melphalan and prednisone for initial treatment of multiple myeloma. N Engl J Med 2008; 359: 906-17

146. Mateos MV, Richardson PG, Schlag R, Khuageva NK, Dimopoulos MA, Shpilberg O, et al. Bortezomib plus melphalan and prednisone compared with melphalan and prednisone in previously untreated multiple myeloma: updated follow-up and impact of subsequent therapy in the phase III VISTA trial. J Clin Oncol 2010;. 28: 2259-66 
147. Potts BC, Albitar MX, Anderson KC, Baritaki S, Berkers C, Bonavida B, et al. Marizomib, a proteasome inhibitor for all seasons: preclinical profile and a framework for clinical trials. Curr Cancer Drug Targets 2011; 11: 254-284

148. Kuhn DJ, Orlowski RZ, Bjorklund CC. Second generation proteasome inhibitors: carfilzomib and immunoproteasome-specific inhibitors (IPSIs). Curr Cancer Drug Targets 2011; 11: 285-295

149. Chen D, Frezza M, Schmitt S, Kanwar J, P Dou Q. Bortezomib as the first proteasome inhibitor anticancer drug: current status and future perspectives. Curr Cancer Drug Targets 2011; 11: 239-53

150. Nayak SB, Bhat VR, Upadhyay D, Udupa SL. Copper and ceruloplasmin status in serum of prostate and colon cancer patients. Indian J Physiol Pharmacol 2003; 47: 108-10

151. Díez M, Arroyo M, Cerdàn FJ, Muñoz M, Martin MA, Balibrea JL. Serum and tissue trace metal levels in lung cancer. Oncology 1989; 46: 230-4

152. Habib FK, Dembinski TC, Stitch SR. The zinc and copper content of blood leucocytes and plasma from patients with benign and malignant prostates. Clin Chim Acta 1980; 104: 329-35

153. Kuo HW, Chen SF, Wu CC, Chen DR, Lee JH. Serum and tissue trace elements in patients with breast cancer in Taiwan. Biol Trace Elem Res 2002; 89: 1-11

154. Rizk SL, Sky-Peck HH. Comparison between concentrations of trace elements in normal and neoplastic human breast tissue. Cancer Res 1984; 44: 5390-4

155. Turecký L, Kalina P, Uhlíková E, Námerová S, Krizko J. Serum ceruloplasmin and copper levels in patients with primary brain tumors. Klin Wochenschr 1984; 62: 187-9

156. Frangoulis M, Georgiou P, Chrisostomidis C, Perrea D, Dontas I, Kavantzas N, et al. Rat epigastric flap survival and VEGF expression after local copper application. Plast Reconstr Surg 2007; 119: 837-43

157. Sen CK, Khanna S, Venojarvi M, Trikha P, Ellison EC, Hunt TK, Roy S. Copper-induced vascular endothelial growth factor expression and wound healing. Am J Physiol Heart Circ Physiol 2002; 282: H1821-7

158. Pan Q, Kleer CG, van Golen KL, Irani J, Bottema KM, Bias C, et al. Copper deficiency induced by tetrathiomolybdate suppresses tumor growth and angiogenesis. Cancer Res 2002; 62: 4854-9

159. Yoshii J, Yoshiji H, Kuriyama S, Ikenaka Y, Noguchi R, Okuda H. The copper-chelating agent, trientine, suppresses tumor development and angiogenesis in the murine hepatocellular carcinoma cells. Int J Cancer 2001; 94: 768-73

160. Provinciali M, Di Stefano G, Fabris N. Dose-dependent opposite effect of zinc on apoptosis in mouse thymocytes. Int J Immunopharmacol 1995; 17: 735-44

161. Murakami M, Hirano T. Intracellular zinc homeostasis and zinc signaling. Cancer Sci 2008; 99: 1515-22

162. Federico A, Iodice P, Federico P, Del Rio A, Mellone MC, Catalano G, Federico P. Effects of selenium and zinc supplementation on nutritional status in patients with cancer of digestive tract. Eur J Clin Nutr 2001; 55: 293-7

163. Prasad AS, Beck FW, Doerr TD, Shamsa FH, Penny HS, Marks SC, et al. Nutritional and zinc status of head and neck cancer patients: an interpretive review. J Am Coll Nutr 1998; 17: 409-18

164. Chakravarty PK, Ghosh A, Chowdhury JR. Zinc in human malignancies. Neoplasma 1986; 33 : 85-90

165. Franklin RB, Costello LC. Zinc as an anti-tumor agent in prostate cancer and in other cancers. Arch Biochem Biophys 2007; 463: 211-7

166. Gupta SK, Singh SP, Shukla VK. Copper, zinc, and Cu/Zn ratio in carcinoma of the gallbladder. J Surg Oncol 2005; 91: 204-8

167. Margalioth EJ, Schenker JG, Chevion M. Copper and zinc levels in normal and malignant tissues. Cancer 1983; 52: 868-72

168. Schwartz AE, Leddicotte GW, Fink RW, Friedman EW. Trace elements in noraml and malignant human breast tissue. Surgery 1974; 76: 325-9 
169. Wong E, Giandomenico CM. Current status of platinum-based antitumor drugs. Chem Rev 1999; 99: 2451-66

170. Eckhardt S. Recent progress in the development of anticancer agents. Curr Med Chem Anticancer Agents 2002; 2: 419-39

171. Abrams MJ, Murrer BA. Metal compounds in therapy and diagnosis. Science 1993; 261: 725-30

172. Galanski M, Arion VB, Jakupec MA, Keppler BK. Recent developments in the field of tumorinhibiting metal complexes. Curr Pharm Des 2003; 9: 2078-89

173. Galanski M, Jakupec MA, Keppler BK. Update of the preclinical situation of anticancer platinum complexes: novel design strategies and innovative analytical approaches. Curr Med Chem 2005; 12: $2075-94$

174. Malaguarnera L, Pilastro MR, DiMarco R, Scifo C, Renis M, Mazzarino MC, Messina A. Cell death in human acute myelogenous leukemic cells induced by pyrrolidinedithiocarbamate. Apoptosis 2003; 8: 539-45

175. Schreck R, Meier B, Männel DN, Dröge W, Baeuerle PA. Dithiocarbamates as potent inhibitors of nuclear factor kappa B activation in intact cells. J Exp Med 1992; 175: 1181-94

176. Reymond JC. Fight against alcoholism; a new product: antabuse. J Prat Rev Gen Clin Ther 1950; 64: 64-6

177. Johansson B. A review of the pharmacokinetics and pharmacodynamics of disulfiram and its metabolites. Acta Psychiatr Scand Suppl 1992; 369: 15-26

178. Vallari RC, Pietruszko R. Human aldehyde dehydrogenase: mechanism of inhibition of disulfiram. Science 1982; 216: 637-9

179. Meyer RE. Prospects for a rational pharmacotherapy of alcoholism. J Clin Psychiatry 1989; 50: 403-12

180. Cen D, Brayton D, Shahandeh B, Meyskens FL Jr, Farmer PJ. Disulfiram facilitates intracellular Cu uptake and induces apoptosis in human melanoma cells. J Med Chem 2004; 47: 6914-20

181. Chen D, Cui QC, Yang H, Dou QP. Disulfiram, a clinically used anti-alcoholism drug and copperbinding agent, induces apoptotic cell death in breast cancer cultures and xenografts via inhibition of the proteasome activity. Cancer Res 2006; 66: 10425-33

182. Brar SS, Grigg C, Wilson KS, Holder WD Jr, Dreau D, Austin C, et al. Disulfiram inhibits activating transcription factor/cyclic AMP-responsive element binding protein and human melanoma growth in a metal-dependent manner in vitro, in mice and in a patient with metastatic disease. Mol Cancer Ther 2004; 3: 1049-60

183. Scalbert A, Williamson G. Dietary intake and bioavailability of polyphenols. J Nutr 2000; 130(8S Suppl): 2073S-85S

184. Shanafelt TD, Lee YK, Call TG, Nowakowski GS, Dingli D, Zent CS, Kay NE. Clinical effects of oral green tea extracts in four patients with low grade B-cell malignancies. Leuk Res 2006; 30: 707-12

185. Sartippour MR, Heber D, Ma J, Lu Q, Go VL, Nguyen M. Green tea and its catechins inhibit breast cancer xenografts. Nutr Cancer 2001; 40: 149-56

186. Kemberling JK, Hampton JA, Keck RW, Gomez MA, Selman SH. Inhibition of bladder tumor growth by the green tea derivative epigallocatechin-3-gallate. J Urol 2003; 170: 773-6

187. Kavantzas N, Chatziioannou A, Yanni AE, Tsakayannis D, Balafoutas D, Agrogiannis G, Perrea D. Effect of green tea on angiogenesis and severity of atherosclerosis in cholesterol-fed rabbit. Vascul Pharmacol 2006; 44: 461-3

188. Zhang Q, Tang X, Lu Q, Zhang Z, Rao J, Le AD. Green tea extract and (-)-epigallocatechin-3-gallate inhibit hypoxia- and serum-induced HIF-1alpha protein accumulation and VEGF expression in human cervical carcinoma and hepatoma cells. Mol Cancer Ther 2006; 5: 1227-38

189. Kuo PL, Lin CC. Green tea constituent (-)-epigallocatechin-3-gallate inhibits Hep G2 cell proliferation and induces apoptosis through p53-dependent and Fas-mediated pathways. J Biomed Sci 2003; 10: 219-27 
190. Bettuzzi S, Brausi M, Rizzi F, Castagnetti G, Peracchia G, Corti A. Chemoprevention of human prostate cancer by oral administration of green tea catechins in volunteers with high-grade prostate intraepithelial neoplasia: a preliminary report from a one-year proof-of-principle study. Cancer Res 2006; 66: 1234-40

191. Jian L, Xie LP, Lee AH, Binns CW. Protective effect of green tea against prostate cancer: a casecontrol study in southeast China. Int J Cancer 2004; 108: 130-5

192. Nakachi K, Suemasu K, Suga K, Takeo T, Imai K, Higashi Y. Influence of drinking green tea on breast cancer malignancy among Japanese patients. Jpn J Cancer Res 1998; 89: 254-61

193. Golden EB, Lam PY, Kardosh A, Gaffney KJ, Cadenas E, Louie SG, Petasis NA, Chen TC, Schönthal AH. Green tea polyphenols block the anticancer effects of bortezomib and other boronic acidbased proteasome inhibitors. Blood 2009; 113: 5927-37

194. Nam S, Smith DM, Dou QP. Ester bond-containing tea polyphenols potently inhibit proteasome activity in vitro and in vivo. J Biol Chem 2001; 276: 13322-30

195. Landis-Piwowar KR, Kuhn DJ, Wan SB, Chen D, Chan TH, Dou QP. Evaluation of proteasomeinhibitory and apoptosis-inducing potencies of novel (-)-EGCG analogs and their prodrugs. Int $J$ Mol Med 2005; 15: 735-42

196. Kuhn D, Lam WH, Kazi A, Daniel KG, Song S, Chow LM, Chan TH, Dou QP. Synthetic peracetate tea polyphenols as potent proteasome inhibitors and apoptosis inducers in human cancer cells. Front Biosci 2005; 10: 1010-23

197. Landis-Piwowar KR, Huo C, Chen D, Milacic V, Shi G, Chan TH, Dou QP. A novel prodrug of the green tea polyphenol (-)-epigallocatechin-3-gallate as a potential anticancer agent. Cancer Res 2007; 67: 4303-10

198. Landis-Piwowar KR, Wan SB, Wiegand RA, Kuhn DJ, Chan TH, Dou QP. Methylation suppresses the proteasome-inhibitory function of green tea polyphenols. J Cell Physiol 2007; 213: 252-60

199. Shanafelt TD, Call TG, Zent CS, LaPlant B, Bowen DA, Roos M, et al, Phase I trial of daily oral Polyphenon E in patients with asymptomatic Rai stage 0 to II chronic lymphocytic leukemia. J Clin Oncol 2009; 27: 3808-14

200. McLarty J, Bigelow RL, Smith M, Elmajian D, Ankem M, Cardelli JA. Tea polyphenols decrease serum levels of prostate-specific antigen, hepatocyte growth factor, and vascular endothelial growth factor in prostate cancer patients and inhibit production of hepatocyte growth factor and vascular endothelial growth factor in vitro. Cancer Prev Res (Phila) 2009; 2: 673-82

201. Wang P, Aronson WJ, Huang M, Zhang Y, Lee RP, Heber D, Henning SM. Green tea polyphenols and metabolites in prostatectomy tissue: implications for cancer prevention. Cancer Prev Res (Phila) 2010; 3: 985-93

202. Lepley DM, Li B, Birt DF, Pelling JC. The chemopreventive flavonoid apigenin induces G2/M arrest in keratinocytes. Carcinogenesis 1996; 17: 2367-75

203. Janssen K, Mensink RP, Cox FJ, Harryvan JL, Hovenier R, Hollman PC, Katan MB. Effects of the flavonoids quercetin and apigenin on hemostasis in healthy volunteers: results from an in vitro and a dietary supplement study. Am J Clin Nutr 1998; 67: 255-62

204. Manach C, Scalbert A, Morand C, Rémésy C, Jiménez L. Polyphenols: food sources and bioavailability. Am J Clin Nutr 2004; 79: 727-47

205. Kaiser CS, Rompp H, Schmidt PC. Supercritical carbon dioxide extraction of chamomile flowers: extraction efficiency, stability, and in-line inclusion of chamomile-carbon dioxide extract in betacyclodextrin. Phytochem Anal 2004. 15: 249-56

206. Zheng PW, Chiang LC, Lin CC. Apigenin induced apoptosis through p53-dependent pathway in human cervical carcinoma cells. Life Sci 2005; 76: 1367-79

207. Liu LZ, Fang J, Zhou Q, Hu X, Shi X, Jiang BH. Apigenin inhibits expression of vascular endothelial growth factor and angiogenesis in human lung cancer cells: implication of chemoprevention of lung cancer. Mol Pharmacol 2005; 68: 635-43 
208. Gupta S, Afaq F, Mukhtar H. Involvement of nuclear factor-kappa B, Bax and Bcl-2 in induction of cell cycle arrest and apoptosis by apigenin in human prostate carcinoma cells. Oncogene 2002; 21: $3727-38$

209. Birt DF, Mitchell D, Gold B, Pour P, Pinch HC. Inhibition of ultraviolet light induced skin carcinogenesis in SKH-1 mice by apigenin, a plant flavonoid. Anticancer Res 1997; 17(1A): 85-91

210. Chen D, Daniel KG, Chen MS, Kuhn DJ, Landis-Piwowar KR, Dou QP. Dietary flavonoids as proteasome inhibitors and apoptosis inducers in human leukemia cells. Biochem Pharmacol 2005; 69: 1421-32

211. Chen D, Landis-Piwowar KR, Chen MS, Dou QP. Inhibition of proteasome activity by the dietary flavonoid apigenin is associated with growth inhibition in cultured breast cancer cells and xenografts. Breast Cancer Res 2007; 9: R80

212. Wang L, Lee IM, Zhang SM, Blumberg JB, Buring JE, Sesso HD. Dietary intake of selected flavonols, flavones, and flavonoid-rich foods and risk of cancer in middle-aged and older women. Am J Clin Nutr 2009; 89: 905-12

213. Hoensch H, Groh B, Edler L, Kirch W. Prospective cohort comparison of flavonoid treatment in patients with resected colorectal cancer to prevent recurrence. World J Gastroenterol 2008; 14: 2187-93

214. Sekizawa R, Ikeno S, Nakamura H, Naganawa H, Matsui S, Iinuma H, Takeuchi T. Panepophenanthrin, from a mushroom strain, a novel inhibitor of the ubiquitin-activating enzyme. J Nat Prod 2002; 65: 1491-3

215. Tsukamoto S, Hirota H, Imachi M, Fujimuro M, Onuki H, Ohta T, Yokosawa H. Himeic acid A: a new ubiquitin-activating enzyme inhibitor isolated from a marine-derived fungus, Aspergillus sp. Bioorg Med Chem Lett 2005; 15: 191-4

216. Yang Y, Kitagaki J, Dai RM, Tsai YC, Lorick KL, Ludwig RL, et al. Inhibitors of ubiquitin-activating enzyme (E1), a new class of potential cancer therapeutics. Cancer Res 2007; 67: 9472-81

217. Laine A, Topisirovic I, Zhai D, Reed JC, Borden KL, Ronai Z. Regulation of p53 localization and activity by Ubc13. Mol Cell Biol 2006; 26: 8901-13

218. Tsukamoto S, Takeuchi T, Rotinsulu H, Mangindaan RE, van Soest RW, Ukai K, et al. Leucettamol A: a new inhibitor of Ubc13-Uev1A interaction isolated from a marine sponge, Leucetta aff. microrhaphis. Bioorg Med Chem Lett 2008; 18: 6319-20

219. Vassilev LT. MDM2 inhibitors for cancer therapy. Trends Mol Med 2007; 13: 23-31

220. Vassilev LT, Vu BT, Graves B, Carvajal D, Podlaski F, Filipovic Z, Kong N, et al. In vivo activation of the p53 pathway by small-molecule antagonists of MDM2. Science 2004; 303: 844-8

221. Ooi MG, Hayden PJ, Kotoula V, McMillin DW, Charalambous E, Daskalaki E, et al. Interactions of the $\mathrm{Hdm} 2 / \mathrm{p} 53$ and proteasome pathways may enhance the antitumor activity of bortezomib. Clin Cancer Res 2009; 15: 7153-60

222. Duncan SJ, Grüschow S, Williams DH, McNicholas C, Purewal R, Hajek M, et al. Isolation and structure elucidation of Chlorofusin, a novel p53-MDM2 antagonist from a Fusarium sp. J Am Chem Soc 2001; 123: 554-60

223. Clark RC, Lee SY, Boger DL. Total synthesis of chlorofusin, its seven chromophore diastereomers, and key partial structures. J Am Chem Soc 2008; 130: 12355-69

224. Tsukamoto S, Yoshida T, Hosono H, Ohta T, Yokosawa H. Hexylitaconic acid: a new inhibitor of p53-HDM2 interaction isolated from a marine-derived fungus, Arthrinium sp. Bioorg Med Chem Lett 2006; 16: 69-71

225. Nakahashi A, Miura N, Monde K, Tsukamoto S. Stereochemical studies of hexylitaconic acid, an inhibitor of p53-HDM2 interaction. Bioorg Med Chem Lett 2009; 19: 3027-30

226. Kona FR, Buac D, Burger A. Disulfiram, and Disulfiram Derivatives as Novel Potential Anticancer Drugs Targeting the Ubiquitin-Proteasome System in Both Preclinical and Clinical Studies. Curr Cancer Drug Targets 2011; 11: 338-346 
227. Lim HS, Archer CT, Kodadek T. Identification of a peptoid inhibitor of the proteasome 19S regulatory particle. J Am Chem Soc 2007; 129: 7750-1

228. Lim HS, Cai D, Archer CT, Kodadek T. Periodate-triggered cross-linking reveals Sug2/Rpt4 as the molecular target of a peptoid inhibitor of the $19 \mathrm{~S}$ proteasome regulatory particle. J Am Chem Soc 2007; 129: 12936-7

229. Verma R, Peters NR, D’Onofrio M, Tochtrop GP, Sakamoto KM, Varadan R, et al. Ubistatins inhibit proteasome-dependent degradation by binding the ubiquitin chain. Science 2004; 306 117-20 